\title{
Trends in Advanced Functional Material Applications of Nanocellulose
}

\author{
Prachiben Panchal, Emmanuel Ogunsona and Tizazu Mekonnen * \\ Department of Chemical Engineering, University of Waterloo, Waterloo, ON N2L 3G1, Canada; \\ pjpanchal@edu.uwaterloo.ca (P.P.); e2ogunso@uwaterloo.ca (E.O.) \\ * Correspondence: tmekonnen@uwaterloo.ca; Tel.: +1-519-888-4567 (ext. 38914)
}

Received: 24 November 2018; Accepted: 25 December 2018; Published: 30 December 2018

\begin{abstract}
The need to transition to more sustainable and renewable technology has resulted in a focus on cellulose nanofibrils (CNFs) and nanocrystals (CNCs) as one of the materials of the future with potential for replacing currently used synthetic materials. Its abundance and bio-derived source make it attractive and sought after as well. CNFs and CNCs are naturally hydrophilic due to the abundance of -OH group on their surface which makes them an excellent recipient for applications in the medical industry. However, the hydrophilicity is a deterrent to many other industries, subsequently limiting their application scope. In either light, the increased rate of progress using CNCs in advanced materials applications are well underway and is becoming applicable on an industrial scale. Therefore, this review explores the current modification platforms and processes of nanocellulose directly as functional materials and as carriers/substrates of other functional materials for advanced materials applications. Niche functional attributes such as superhydrophobicity, barrier, electrical, and antimicrobial properties are reviewed due to the focus and significance of such attributes in industrial applications.
\end{abstract}

Keywords: cellulose nanocrystals; functional materials; superhydrophobicity; antimicrobicity; barrier properties

\section{Introduction}

Cellulose, lignin, starch, chitosan, protein, triglycerides, natural gums, and polyphenols constitute an interesting nature-derived and renewable feedstock for advanced material applications. Among these feedstocks, cellulose is the most abundant biopolymer on earth with an approximate annual production of $10^{10}$ tons [1,2]. As such, it has been an immense source for the paper and textile industries for thousands of years. Cellulose is a homopolymer with a linear chain of six carbon ring, anhydro-D-glucose unit (AGU) monomers. Each AGU monomer in a chair conformation is linked with a $\beta(1 \rightarrow 4)$ glycosidic bonds [3,4].

Overall, cellulose is a rigid and stiff polysaccharide that has tensile strength comparable to other commercial fibers such as carbon fiber [5]. Reinforcement of high melting temperature polymers with modified biomass has extensively been reported [6-11]. Likewise, it has also been extensively reported that the addition of cellulose fibrils in various forms to produce polymeric composites can greatly enhance mechanical properties of the base polymeric materials at significantly lower loadings compared to other biomasses [12-17]. Forms of cellulose fibrils can range from cellulose powders to microcrystalline cellulose and nanocrystalline cellulose. In the last two decades, a substantial and continuing interest in the utilization of cellulose nanoparticles in material applications is observed. This is accrued from a breakthrough in the largescale production of nanocellulose, as well as their multifaceted benefits in traditional polymer composites and functional materials. Nanocellulose is a material extracted from cellulose which has one or more dimensions in the nanometer range of 100 
or less [2,18], and considered as the next generation renewable reinforcing agents for the production of biocomposites, and especially for advanced functional materials applications.

\subsection{Nanocellulose}

Nanocellulose is a generic name referring to different cellulose nanoparticles (CNPs) such as bacterial cellulose, microbial cellulose, cellulose nanocrystals, cellulose nanofibrils, cellulose nanofibers, and cellulose nanowhiskers [19]. Amongst the variety of CNPs, the two major structures are cellulose nanocrystals (CNC) and cellulose nanofibers (CNF) [2,20]. The extraction process of these two structures from the feedstock and their morphology are the two main differences between these CNPs $[20,21]$. Cellulose nanocrystals are extracted through chemical processes such as hydrolysis and they have a rod -like structure. Contrarily, cellulose nanofibers contain web-like network and are mainly extracted through mechanical and chemo-mechanical processes [5,20,21].

Similar to other bio-based materials used for advanced materials applications [22-24], the renewability, biodegradability, high strength, low density, high crystallinity, high aspect ratio, and unique optical properties make CNCs highly desirable materials in several advanced and functional material applications [20,25]. CNCs can be isolated from bioresources such as wood, cotton, hemp, linen, flax, tunicate (aquatic invertebrate) $[5,17,18,20,21,25]$. It can also be generated by a bottom-up or biosynthesis from simple molecules. Bacterial nanocellulose produced by bacteria and algae via fermentation of sugar is a typical example of such bottom-up approach [26]. The properties of CNCs can vary depending on bio-sources and the extraction process used. Some of the extensively researched material applications of CNCs include plastic composites, paints and coatings, packaging films, cement, rubber products, biomedical applications (e.g., pharmaceuticals, diagnostic imaging, drug delivery, tissue engineering materials), sensors, and many more $[19,27,28]$.

\subsection{CNC Characteristics}

Cellulose exists in seven allomorphs: Cellulose $\mathrm{I}_{\alpha}, \mathrm{I}_{\beta}, \mathrm{II}_{\mathrm{III}}, \mathrm{III}_{\mathrm{II}}, \mathrm{IV}_{\mathrm{I}}$ and $\mathrm{IV}_{\mathrm{II}}$, where cellulose I is the most crystalline structure with the highest axial elastic modulus $[4,18]$. The two polymorph of cellulose $\mathrm{I}$, cellulose $\mathrm{I}_{\alpha}$ and $\mathrm{I}_{\beta}$, coexists where $\mathrm{I}_{\beta}$ is more thermally stable than $\mathrm{I}_{\alpha}$ due to weaker hydrogen bond in $\mathrm{I}_{\alpha}$ [18]. CNC contains $64-98 \% \mathrm{I}_{\beta}$ depending on the source [18]. CNCs are found in rod shape. Typically, they can be 3-5 $\mathrm{nm}$ wide and $50-500 \mathrm{~nm}$ long [18]. However, CNC from tunicate can be as wide as $20 \mathrm{~nm}$ [18]. The larger dimensions for CNCs derived from tunicate is a result of highly crystalline tunicate cellulose, which contains less amorphous regions that leave behind larger crystalline region [29]. One of the most attractive properties of CNC is its high aspect ratio. This is because the functional application of $\mathrm{CNC}$ is dependent on the aspect ratio in several cases. For instance, the use of $\mathrm{CNC}$ as a reinforcing agent relies on its higher aspect ratio. On the other hand, CNCs with uniform crystallinity and lower aspect ratio are beneficial in renewable liquid crystals applications [30,31]. Table 1 shows that the variation in aspect ratio of nanocrystals depending on the source of CNC. Overall, nanocrystals derived from sea plant and animal has significantly higher aspect ratio as compared to those extracted from wood and cotton.

Table 1. Aspect Ratio of cellulose nanocrystals (CNC) Derived from Different Sources.

\begin{tabular}{|c|c|c|c|c|}
\hline Source & Length (nm) & Width (nm) & Aspect Ratio * & Reference \\
\hline Bacterial & $640-1070$ & $12-22$ & 50 & [32] \\
\hline Cotton & $100-300$ & $4-10$ & 29 & [2] \\
\hline Flax & $100-500$ & $10-30$ & 15 & [33] \\
\hline Ramie & $150-250$ & $6-8$ & 29 & [34] \\
\hline Sisal & $150-350$ & $3-5$ & 62 & [35] \\
\hline Valonia (Sea plant) & $1000-2000$ & 20 & 75 & [2] \\
\hline Tunicate (Sea animal) & 500-2000 & $10-20$ & 83 & [2] \\
\hline Wood & $100-200$ & $3-15$ & 17 & [2] \\
\hline
\end{tabular}

* Aspect Ratio $=$ Aspect ratio calculated using average length and width. 
It is important to highlight that cellulose nanocrystals are a highly crystalline fraction of cellulose. CNCs have degree of crystallinity of $54-88 \%$ depending on the amorphous content present in the feedstock, and the production process [18]. Nanocrystals derived from tunicate have been reported to have the highest crystallinity, which ranges from $85-100 \%$ [18]. As a result of the higher crystallinity caused by hydrogen bonding, cellulose nanocrystals are rigid and stiff. CNCs are also rich in hydroxyl groups $(-\mathrm{OH})$ since each AGU unit offers one primary and two secondary $-\mathrm{OH}$ groups leaving it open to endless modification and functionalization possibilities [18]. Moreover, the high surface area to volume ratio of $\mathrm{CNC}$ s further facilities surface functionalization or other - $\mathrm{OH}$ chemistry efforts making it suitable for various advanced functional material applications [36].

Due to the sheer numbers of published review articles on CNCs with focuses on their modifications and applications towards polymer composites and nanocomposites, extraction and purification processes and determinations of their properties and characteristics just to mention a few, these subjects will only be highlighted. To the best of our knowledge, only few review articles were published on advances in applications of cellulose nanocrystals covering several topics. For instance, the review article by Grishkewich et al. [37] covered topics ranging from tissue engineering to gene delivery and energy. However, due to growing interests, research being conducted and achieved on CNC continually and especially in niche areas such as wettable surfaces, coatings, several applications of biotechnology, and electronics, there is need to update and disseminate the new developments achieved and knowledge gained. Therefore, this review focuses on the current advanced material functionalization of CNCs geared towards these areas as described in the schematic shown in Figure 1.

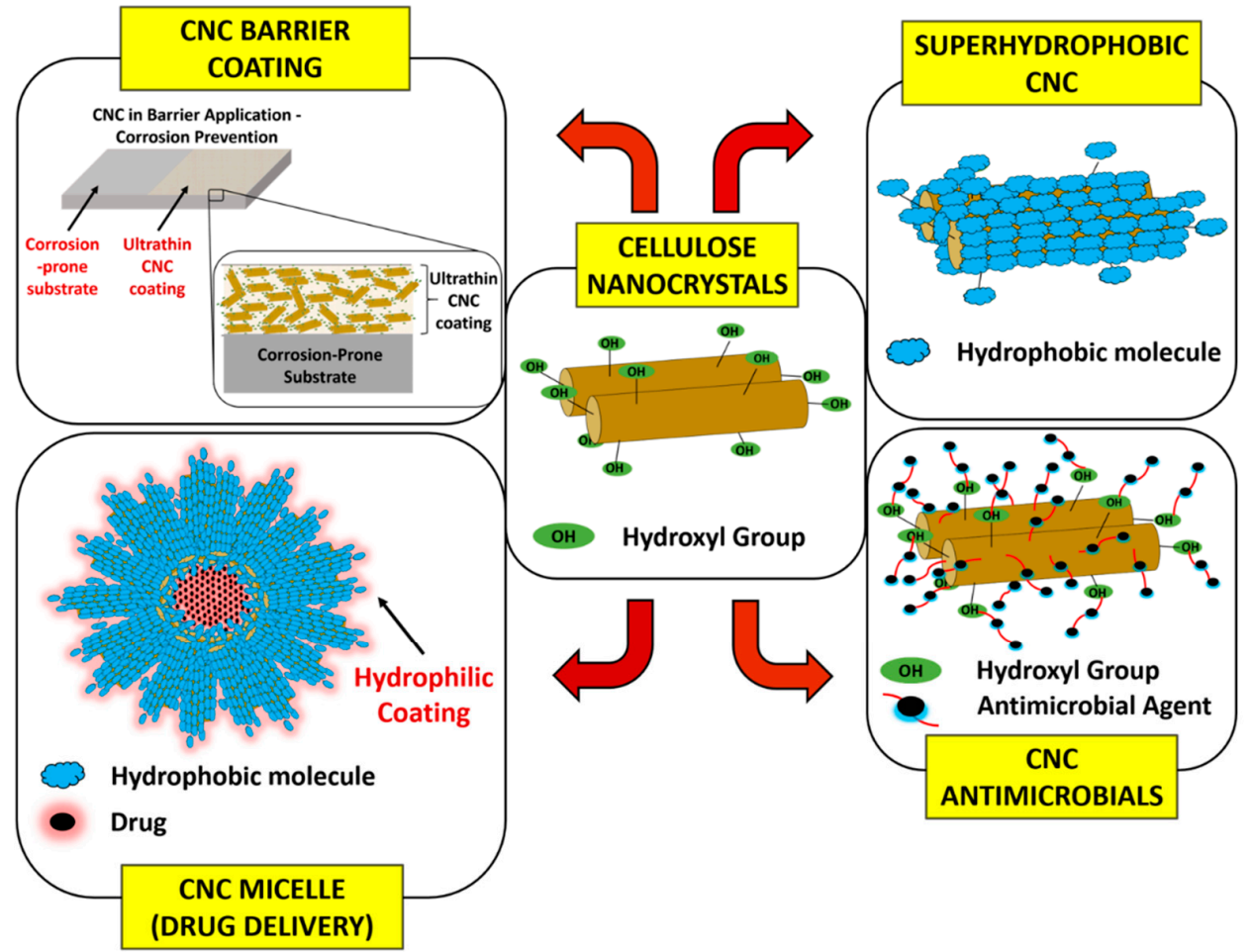

Figure 1. Some application of cellulose nanocrystals (CNCs) and nanofibrillated cellulose (NFCs) in advances functional materials applications.

\section{Cellulose Nanocrystals in Wettable Applications}

Wettability of a substrate or surface is the ability of that surface to create intermolecular interactions such as cohesive and adhesive forces when typically, in contact with a liquid. The degree of wettability is determined by the aforementioned forces which also govern the contact angle (CA) between the substrate and liquid. The CA subsequently determines if a material or substrate is hydrophobic, hydrophilic or their extremes. In recent years many researchers have been drawn towards 
the development of hydrophobic nanomaterials due to the increasing demand in both academic and industrial sectors. Hydrophobicity is an important property to determine the application of nano-composites. Hydrophobic materials with self-cleaning, antifouling, water repellency, and reduced friction properties are highly desirable for industrial applications. CNCs are known for their strength and commonly used as reinforcing agents. However, the application of CNC is currently limited because it cannot be readily incorporated into many polymer matrices that are typically hydrophobic due to its high hydrophilicity. Thus, hydrophobic modification of CNC can lead to better dispersion in non-polar and hydrophobic matrices. Furthermore, hydrophobic CNC surface can also be used as a coating agent for marine vehicles, biomedical devices, windows, textiles, paints, and many other applications. The advancement of hydrophobic CNC surface can open doors to many commercial applications of this abundant biopolymer found in nature.

In nature, butterfly wings, lotus and other plant leaves are greatly studied for their superhydrophobicity $[38,39]$. Lotus leaves known for its self-cleaning properties has hierarchical rough structure containing two levels of roughness [38]. Superhydrophobic properties of lotus known as lotus-effect have inspired the synthesis of many artificial hydrophobic materials. An important aspect to study while investigating hydrophobicity is the water contact angle (WCA). A hydrophilic material has a WCA of less than $90^{\circ}$, a hydrophobic material has a WCA higher than $90^{\circ}$ while materials displaying WCA greater than $150^{\circ}$ are superhydrophobic [39,40]. Various relations including Young's equation, Wenzel equation and Cassie equation have been developed to determine WCA [39]. Along with water contact angle, another important characterization property of hydrophobicity is sliding angle. Sliding angle is a measure of tilt angle between the surface and substrate droplet at which droplet starts to roll off of the surface. Superhydrophobic material has sliding angle less than $10^{\circ}$, which is often used to describe the anti-water repellency property $[39,41]$.

Hydrophobicity can be controlled through chemical modification or surface roughness. Reduction of surface energy through chemical modifications and enhanced roughness, both the factors must be simultaneously controlled to achieve superhydrophobicity [42]. Preparation of superhydrophobic materials involves harsh chemical and physical treatments. Chemical modification to obtain hydrophobicity include attachments of low surface energy molecules such as fluorinated agents [43], silanes [42], organic hydrophobic chains [44] and etc. Table 2 lists various chemical treatments and attachments to cellulose -based materials such as cotton, paper, and cellulose nanocrystals.

Table 2. Hydrophobic Treatment of Cellulose-based Materials (PFSC: perfluorooctylated quaternary ammonium silane coupling agent; TEOS: Tetraethyl orthosilicate).

\begin{tabular}{cccc}
\hline Surface & Modification & WCA & Reference \\
\hline CNC & Pentafluorobenzoyl chloride & $112^{\circ}$ & {$[43]$} \\
CNC & Castor Oil & $97^{\circ}$ & {$[44]$} \\
CNC & Stearyltrimethylammonium chloride & $71^{\circ}$ & {$[45]$} \\
Cotton & Silica sol treated with PFSC & $145^{\circ}$ & {$[46]$} \\
Paper & TEOS and tridecafluorooctyl triethoxysilane & $170^{\circ}$ & {$[41]$} \\
\hline
\end{tabular}

Although chemical modification has been the traditional approach to functionalize the surface of a material for a number of applications, a recent trend in enhancing the surface roughness is providing some interesting hydrophobic characteristics in several materials. Increasing surface roughness plays a key role in enhancing water repellency [46]. In this, air, which is very hydrophobic (water contact angle $180^{\circ}$ ) gets trapped between the grooves of the roughness [47]. When a water droplet rests on the surface it comes in contact with the entrapped hydrophobic air leading to hydrophobicity enhancement [47]. Surface roughness strategies such as etching, laser, electrospinning and etc. are also commonly used $[39,48]$.

Salajkova et al. [45] employed quaternary ammonium salts modification to bring about hydrophobic modification of CNCs. In this study, four different quaternary ammonium salts were used 
for the CNC modification. Figure 2. shows the attachment of (1) stearyltrimethylammonium chloride as well as the structure of other three quaternary ammonium salts, (2) phenyltrimethyl-ammonium chloride, (3) glycidyl trimethylammonium chloride, (4) diallyldimethylammonium chloride [45]. The highest WCA for stearyltrimethylammonium chloride modified CNC was $71^{\circ} \mathrm{C}$. Although great improvement was observed in WCA of the CNC surface, a higher WCA $\left(>90^{\circ}\right)$ is typically desirable for employing the hydrophobicity of $\mathrm{CNC}$ for advanced material applications.

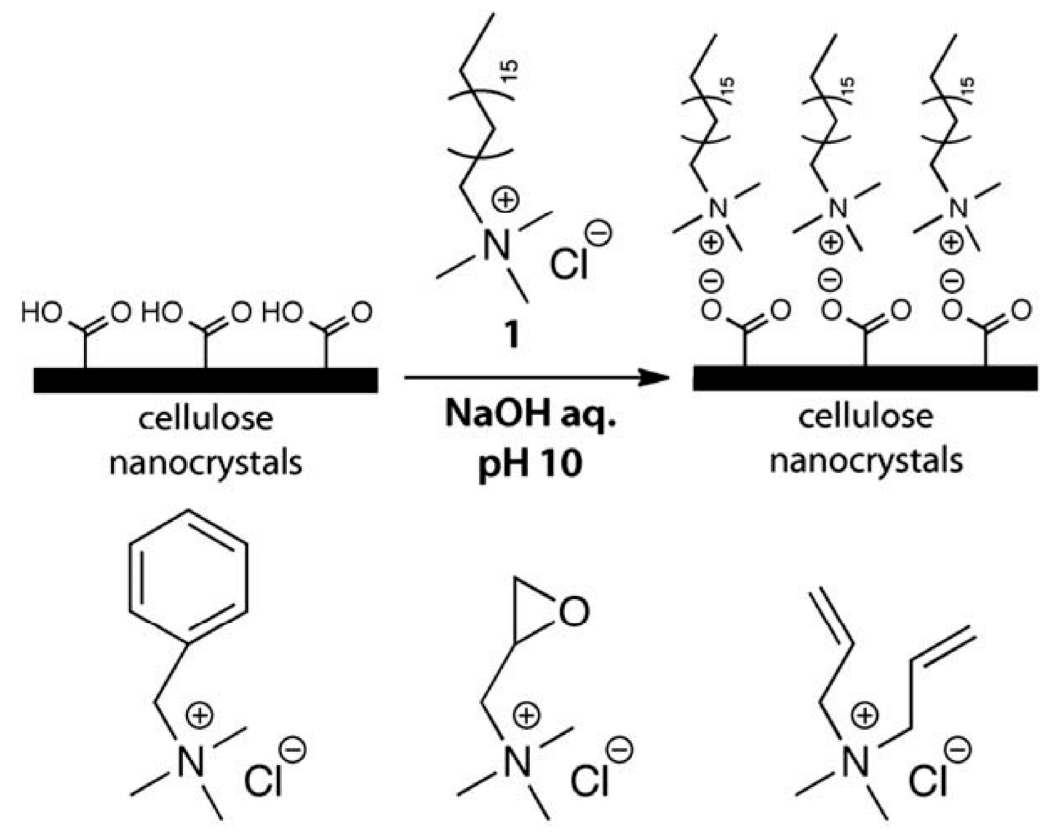

Figure 2. CNC modified by Quaternary Ammonium Salts. Reproduced with permission from Salajková et al. [45]. RSC copyright (C) 2012.

Silica nanoparticles are widely used for hydrophobic modification of cellulosic materials. Tetraethyl orthosilicate (TEOS) prepared through sol-gel process was used for the hydrophobic treatment of cotton fabric [49]. Silica is not hydrophobic therefore fluorinated silane and alkylanated silane, or other alternative water repellent agents are commonly used to achieve water repellency [49]. Silica, TEOS, sol treated with perfluorooctylated quaternary ammonium silane coupling agent (PFSC) showed water contact angle of $145^{\circ}$ proving PFSC to be very effective [46].

Paper, a major product from cellulose, was coated with TEOS sol and tridecafluorooctyl triethoxysilane to produce a hydrophobic surface [41]. The modified paper had a WCA greater than $170^{\circ}$ and sliding angle less than $7^{\circ}$ displaying superhydrophobic properties [41]. Instead of only using silica nanoparticles, the treatment of silica with fluorinated compounds often offers better water repellency. Salam et al. [43] reported fluorine-based modification of nanocellulose to obtain hydrophobic and oleophobic properties. Figure 3 shows the modification of $\mathrm{CNC}$ surface through fluorinating agents. The modified CNC displayed a water contact angle of $112^{\circ}$ and maintained $80^{\circ}$ even after $1200 \mathrm{~s}$ [43]. However, due to the surface modification, the crystallinity of cellulose nanocrystals was slightly modified. The modified CNC had a crystallinity index of $82 \%$ while the unmodified CNC displayed a higher crystallinity index, 91\% [43].

Shang et al. [44] has reported another approach of producing hydrophobic CNC, by attaching castor oil on the surface of the CNC. Castor oil containing hydroxylated fatty ricinoleic acid triglyceride (RTA), was attached onto to CNC surface via grafting-onto modification approach while using diisocyanate as a coupling agent [44]. Only one hydroxyl group was maintained active while other two were terminated in order to link one end of diisocyanate with castor oil and another with the $\mathrm{CNC}$. Successful grafting led to reduction in the surface energy. The increase in water contact angle of 
grafted material to $97^{\circ}$ also suggested hydrophobicity of the nanocellulose [44]. The resulting material was dispersible in non-polar solvents such as toluene and ethyl ether [44].

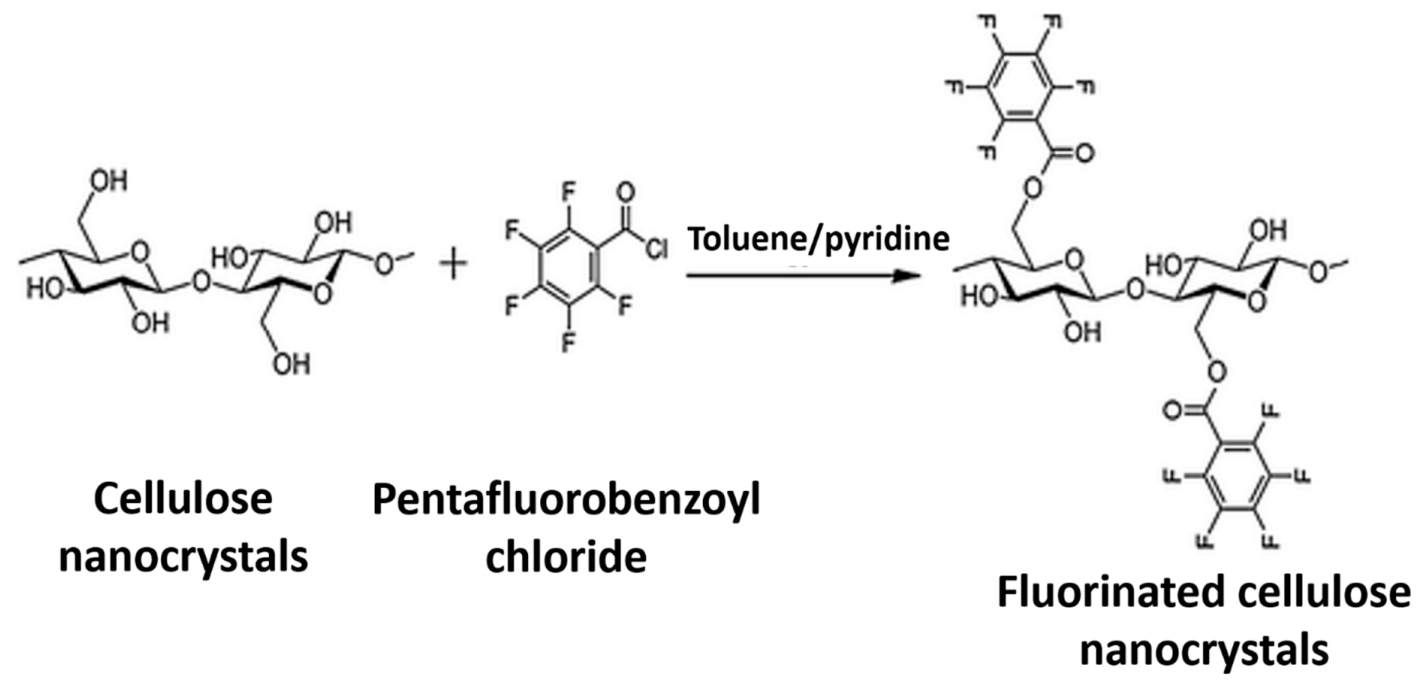

Figure 3. Hydrophobic modification of CNC via fluorine-based agents. Reproduced with permission from Salam et al. [43]. Springer copyright (C) 2015.

Hydrophobic surfaces provide the advantage of efficient and enhanced performance of materials when used in targeted applications. Hydrophobic and superhydrophobic surfaces are highly desirable for marine equipment coating. Watercrafts, marine platforms, offshore rigs and jetties are highly vulnerable to fouling. As a result, operational and maintenance cost for sustaining water-based structure is relatively high. Thus, hydrophobic surfaces with the correct combination of surface roughness and chemical modification can reduce the wetting behavior that result in minimizing attacks from marine organisms and corrosions. CNCs with great reinforcing ability can be modified to achieve both superhydrophobicity and antimicrobial properties. Dual function CNC can greatly enhance the performance of underwater objects and marine equipment.

Surface containing hydrophobic coatings is desirable for self-cleaning windows, satellite dishes, solar energy panels, photovoltaics, exterior architectural glass [39]. Furthermore, water repellent paper can have practical application for valuable printable paper, filter paper, packaging and photographs [47]. Recently, textiles with water repellency, anti-stain and self-cleaning properties are of interest in outdoor sporting textile applications [49]. Due to the increasing demand of hydrophobic materials, researchers are developing various approaches for hydrophobic modification of CNCs. Despite numerous research being conducted in this field, commercial applications of hydrophobic and superhydrophobic materials is limited due to susceptibility of CNCs to environmental degradation over time $[41,50]$.

Zhou et al. recently developed a superhydrophobic micro fibrillated cellulose aerogel (HMFCA) to efficiently separate oil from water [51]. In this study, silanization in an ethanol solution containing methyltriethoxysilane (MTES) was used to modify the aerogel by introducing polysiloxane groups on the surface of the HMFCAs. Prior to silanization, the HMFCA was oxidized to introduce hydroxyl groups, which was used as anchor points for the silanization process. The polysiloxane groups are highly water repulsive (hydrophobic) while allowing the absorption of oil (lipophilic) into the porous structure of the aerogel. The resulting modified aerogel when immersed in oil-contaminated water exhibited oil selective capability of up to $159 \mathrm{~g} / \mathrm{g}$. Experimental runs after 30 cycles revealed a reusability capacity of up to $92 \mathrm{~g} / \mathrm{g}$ which was approximately $58 \%$. Figure 4 a shows the contact angle of the unmodified HMFCA and modified HMFCAs with different MTES concentrations of 1, 2 and $3 \mathrm{~mL}$ which correspond to HMFCA-1, HMFCA-2 and HMFCA-3, respectively. It was observed that the contact angle increased with increasing MTES concentration up to 151.8 degrees, indicating 
its superhydrophobic nature. Figure $4 \mathrm{~b}-\mathrm{d}$ show the before and after modification of the aerogels and flotation of the modified aerogel in water due to the reduced surface energy created by the modification process. Figure 3e shows the possible reaction scheme for the modification of the hydrophilic aerogel into lipophilic aerogels. This study shows the great potential of micro fibrillated celluloses and possibly CNCs to be used on a large scale for oil spill clean ups from offshore rigs and leaking underwater pipelines.
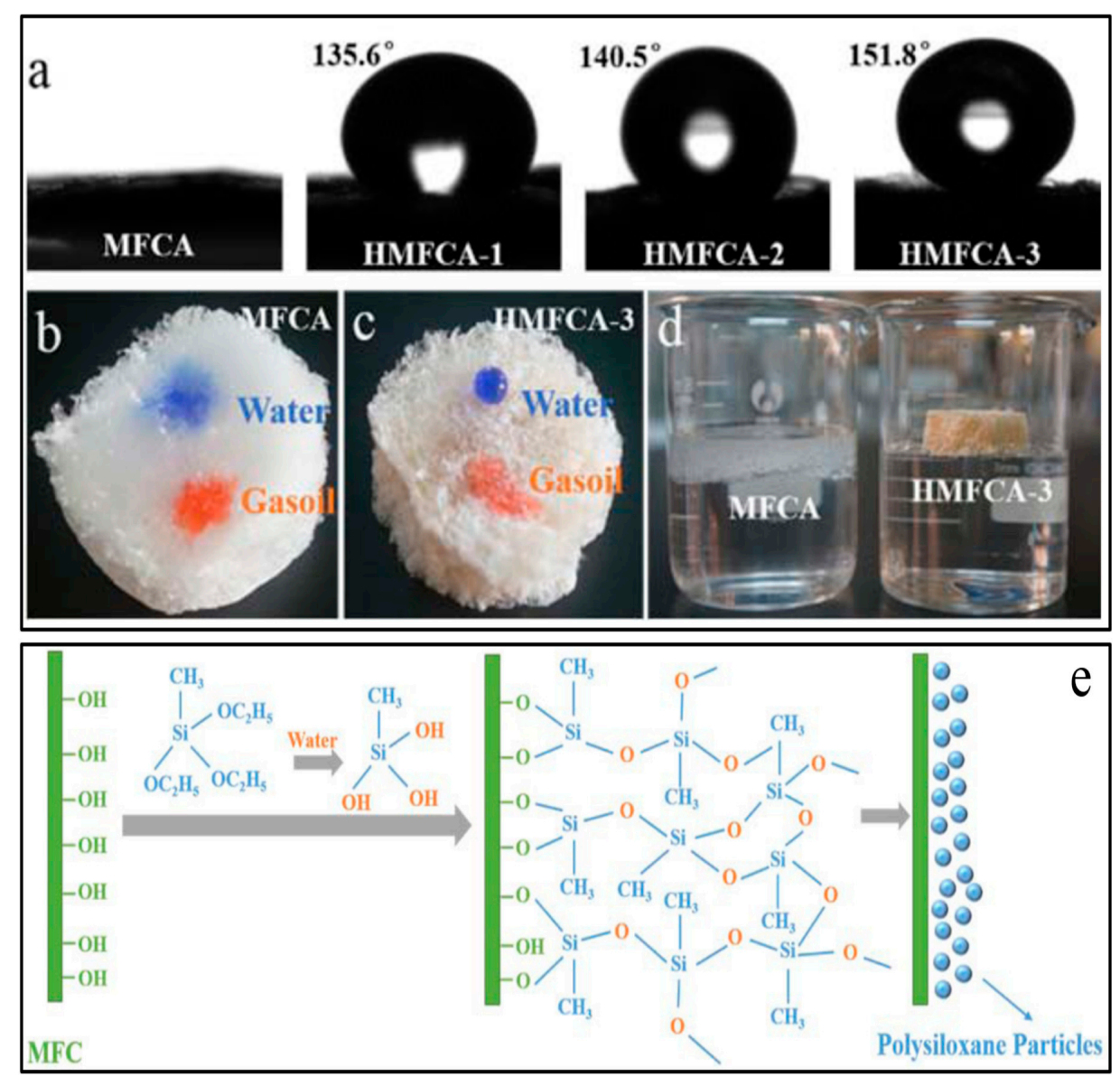

Figure 4. (a) Contact angle measurement of unmodified and modified micro fibrillated cellulose aerogel (MFCAs) with 1, 2 and $3 \mathrm{~mL}$ methyltriethoxysilane (MTES) concentrations. (b,c) Water/oil selectivity of unmodified MFCA and modified MFCA with $3 \mathrm{~mL}$ of MTES with both water and oil absorbed in the unmodified MFCA while only oil is absorbed in the modified MFCA. (d) Modified MFCA floating on water while unmodified MFCA sinking into water. (e) Schematic representation of silinization grafting of methyltriethoxysilane (MTES) onto micro fibrillated cellulose (MFC). Reproduced with permission from Zhou et al. [51]. ACS publications copyright (C) 2016.

Water/oil selectivity of unmodified micro fibrillated cellulose aerogel (MFCA) and modified MFCA with $3 \mathrm{~mL}$ of MTES with both water and oil absorbed in the unmodified MFCA while only oil is absorbed in the modified MFCA. Oil-water separation tests were also performed using a stainless-steel mesh treated with the superhydrophobic CNCs. Different oils such as toluene, N-haxane, xylene and cyclohexane were used to determine the efficiency of the treated mesh in separating the oil from the water while reusing the mesh for 40 cycles. The result from this test revealed that the mesh was able to efficiently remove all types of oils with a separation rate of at least $97.37 \%$. Analogous to the above work, oil/water separation using superhydrophobic cotton fabric coated with CNC has been published and shown to have excellent results with a $98 \%$ separation efficiency with the coated cotton fabric capable of being reused without detriment to the separation efficiency [52]. The reusability, 
durability and efficiency of oil water separation most likely stems from the strong covalent bonds on the cellulose surface as well as the excellent mechanical properties of the cellulose nanocrystals such as the strength, stiffness and wear resistance. Similar to the study by Zhou et al. [51], these works demonstrate the capability of superhydrophobic CNCs when geared towards applications such as water contaminant separation.

In a similar study by Huang et al., CNCs were treated with $1 \mathrm{H}, 1 \mathrm{H}, 2 \mathrm{H}, 2 \mathrm{H}$ perfluorodecyltrichlorosilane in the liquid phase through water-ethanol-toluene exchanges to produce superhydrophobic CNCs [53]. In this reaction, the trichlorosilane groups react with the hydroxyl groups of the CNCs to form a covalent bond while leaving the highly fluorinated tail dangling. The group reduces the surface energy and therefore makes it superhydrophobic. The superhydrophobic CNCs were then applied to different substrates such as wood, glass and stainless-steel mesh. Each substrate was first sprayed with a quick-drying adhesive before being sprayed with the superhydrophobic CNCs and allowed to dry. Self-cleaning and water contact angle tests were performed on the treated substrates and are shown in Figure 4. It can be observed from Figure $5 a, b$ that the coated wood and glass substrates exhibited superior hydrophobic characteristics with high contact angles of 158 and 156 degrees, respectively. The self-cleaning efficiency of the uncoated and coated substrates with the superhydrophobic CNCs can be observed in Figure $5 c, d$, respectively. The high degree of self-cleaning can be applied to marine equipment and vessel surface, thereby allowing for increased buoyance and reduced need for expensive and frequent maintenance. Though, the substrate used by Huang et al. [53] might pose a challenge when it comes to large scale application due to the weight and possible high cost, it is highly durable and can withstand impacts and bumps over several cycles. Those used by Zhou et al. [51] and Cheng et al. [52] are light-weight, readily available and can be mass produced. However, it might not be as durable as the stainless-steel material in the long run. Regardless of the choice of material, the application of modified CNCs for superhydrophobic material applications is promising and on track for industrial scale use.

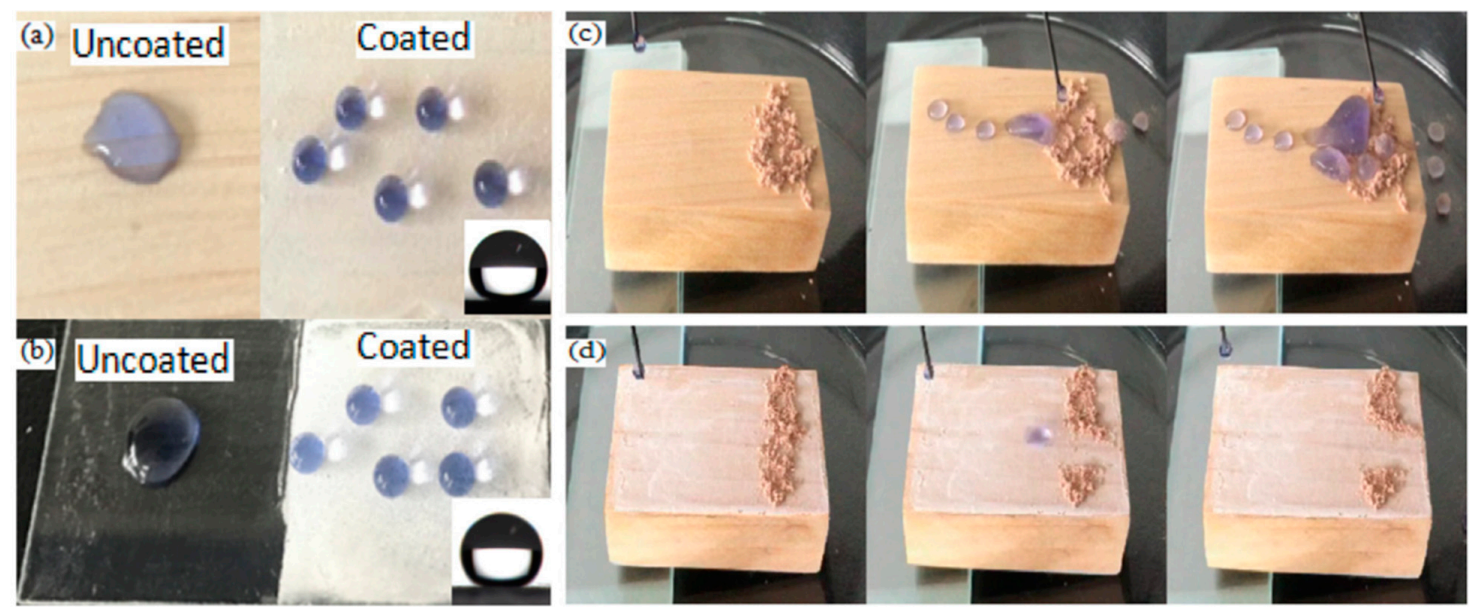

Figure 5. Demonstration of superhydrophobic coating from modified CNC with high contact angle on wood (a) and glass (b). Self-cleaning capability of uncoated (c) and coated (d) wood. Reproduced with permission from Huang et al. [53]. Elsevier copyright (c) 2018.

Recently, Gou et al. developed a process to modify the surface of nanofibrillated cellulose (NFC) films to render portions of the films either superhydrophobic or superhydrophilic [54]. In this process, the NFC film was immersed in trichlorovinylsilane (TCVS)-toluene solution to allow for the growth of TCVS silicone nanofilaments on its surface through hydrolysis and polycondensation to form crosslinked porous polymeric silicone nanofilaments on the surface (TCVS-SNFs). This film was further modified to form superhydrophobic surfaces by exposure to ultraviolet light in the presence of hydrophobic thiol compounds such as $20 \%(v / v) 1 \mathrm{H}, 1 \mathrm{H}, 2 \mathrm{H}$, $2 \mathrm{H}$-perfluorodecanethiol solution in ethyl acetate or $20 \%(v / v)$ 1-butanthiol in ethanol. In order to 
selectively form superhydrophilic surfaces on the superhydrophobized film, it was further exposed to ultraviolet light in the presence of cysteamine or 2-mercaptoethanol as hydrophobic moieties leaving only areas which was intended to be exposed to a UV light. The use of ultraviolet light was to catalyze the reaction between the TCVS-SNFs on the surface of the film and the hydrophobic moieties and between the hydrophobic moieties and the hydrophilic moieties through photo-induced thiol-ene reaction. Likewise, a slippery NFC surface was created by incorporating lubricant fluid into an already superhydrophobic NFC films until complete saturation of the fibrils was acheived. Figure 6a demonstrates the process of superhydrophilic-superhydrophobic dual surface modification of an NFC film using photo-induced thiol-ene reaction by UV light exposure. Figure $6 \mathrm{~b}$ shows the mapping of dual superhydrophobic-hydrophilic surfaces using secondary ion mass spectrometry coupled with time-of-flight mass analysis. This was used to determine the elemental and molecular identities of the dual surface. Further geometric designs were made and are shown in Figure $6 c$ with different patterns of the hydrophobic-hydrophilic surfaces using dyed water solutions to clearly identify each region. The mechanism of reaction, stepwise functionalization and modification of the NFC films to form both super-hydrophobic and hydrophilic surfaces and slippery NFC films are shown in Figure 6d. Such findings can lead to an extensive utilization in biotechnology and biomedical applications such as specifically designed films, which can be used to repel or attract specific biological moieties in the body due to their polar or nonpolar characteristics.

In the studies above, irreversible superhydrophobic surfaces were developed and shown to be extremely efficient. However, in a very recent study, a reversible superhydrophobic/superoleophilicsuperhydrophilic/superoleophobic transition of modified cellulose fabric was developed and designed by Fan et al. [55]. Smart or transition-reversible superhydrophobic-superhydrophilic cellulose fabric was formed by introducing the fabric into an aqueous solution of sodium hydroxide, distilled water and urea for a specific period of time after which it was treated in a zinc chloride aqueous solution to allow zinc cations and chlorine anions be absorbed onto the surface of the cellulose fibers. The fibers are swollen and allowed for the ions to penetrate into the pores. The loaded fabric was steamed to imprint the ions on the fabric fibers. The treated fabric was then washed repeatedly with deionized water and baked thereafter. The baking process was done to shrink the fibers, thereby physically locking the imprinted ions in the pores of the fibers as water is removed and shrinkage occurs. This fabric now loaded with zinc oxide ( $\mathrm{ZnO}-\mathrm{CFs}$ ) was further modified to give it a superhydrophobic-superhydrophilic reversible-transition surface by dipping it into a solution of lauric acid and ethanol. Thereafter, soaked in another solution of sodium hydroxide, ethyl alcohol and water. Figure $7 \mathrm{a}-\mathrm{d}$, displays the micrographs of the cellulose fibers before and after modification with $\mathrm{ZnO}, \mathrm{ZnO}$ and lauric acid and $\mathrm{ZnO}$, lauric acid, sodium hydroxide and ethyl alcohol aqueous solution, respectively. It can be observed that there is the presence of $\mathrm{ZnO}$ attached to the fiber surface after modification which created a micro-nano rough surface structure which was partially ascribed as a factor in the formation of hydrophobic and hydrophilic surfaces thereafter. Likewise, in Figure 7e, the schematic demonstrates the step taken in achieving this process. Readers should refer to the published work for a well detailed experimental procedure and for more information as needed [55]. It was found that the reversable wettability of the modified cellulose fibric maintained its properties such as separation efficiency and wettability phases even after 20 reversal cycles between hydrophobicity and hydrophilicity. The mechanism behind the hydrophobic to hydrophilic transition of the fabric was ascribed to the formation of sodium carboxylate after the scissioning of chelation between $\mathrm{ZnO}$ and carboxylate anion formed during the modification process. The newly formed sodium carboxylate would move to the liquid phase from the solid-liquid interface, thereby increasing the solid-surface free energy as a resulting in the local reduction of water surface tension from the loss of low free energy alkyl chains. This subsequently results to wettability reversal or transition. This study not only advanced the science of oil/water separation but also took it a step further by broadening the application scope to include the removal of water from oil and not just oil from water. In cases where the contaminant is water, it can be removed by using the smart cellulose fabric 
in its superhydrophilic/superoleophobic form, on the contrary, while it is in its reversed form of superhydrophobicity/superoleophilicity, it can remove oil from water simply by immersing it in a solution to stimulant the transition back to the former as described above. These applications can be geared towards the oil industry where purity of oil is critical to its final use or in industries where oil spill cleanup into large bodies of water is required.

(a)

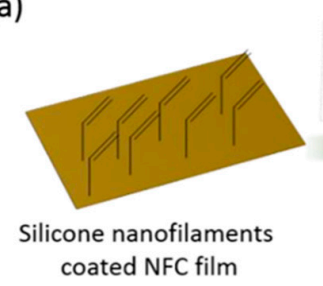
coated NFC film

\section{UV Light}

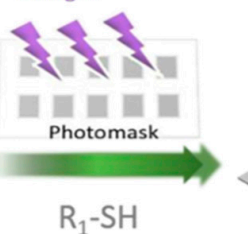

$\mathrm{R}_{1}-\mathrm{SH}$

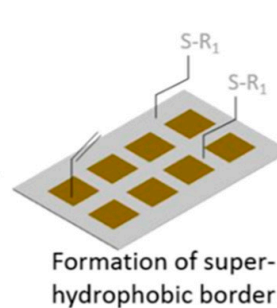

hydrophobic border
UV Light

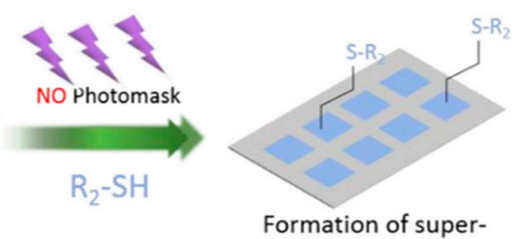

hydrophobic/hydrophilic pattern

(b)
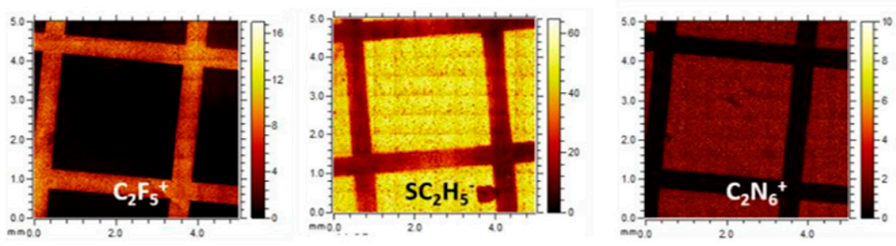

(c)

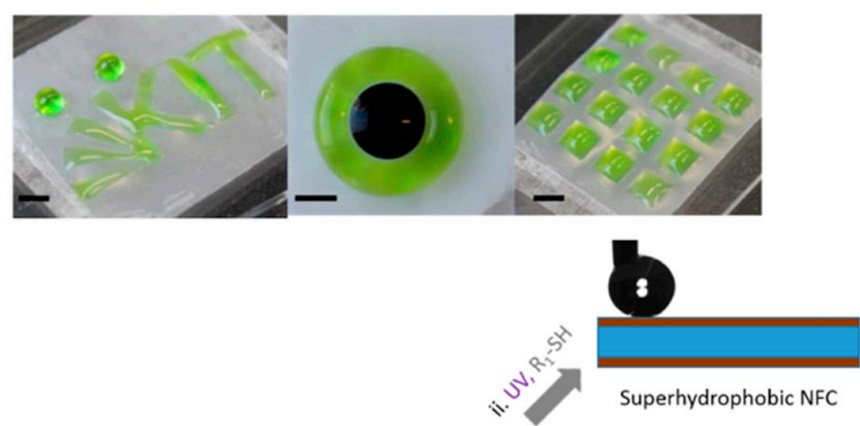

(d)

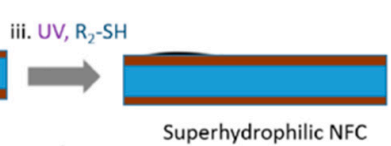

$R_{1}$ :
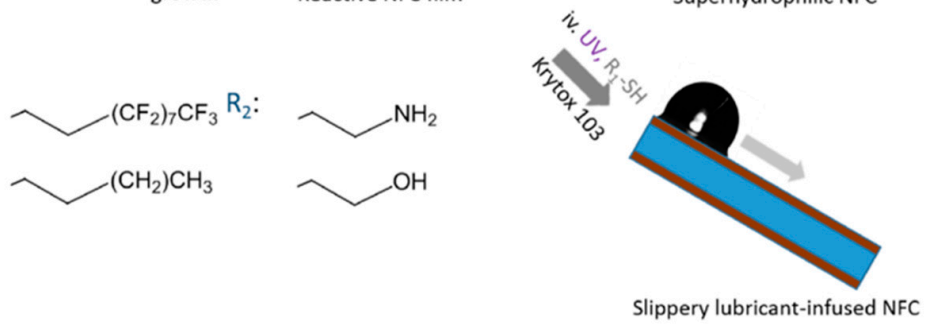

Figure 6. (a) modification of NFC films to produce superhydrophobic/superhydrophilic patterns. (R1 and R2-superhydrophobic and superhydrophilic moieties grafted on NFC film surfaces), (b) secondary ion mass spectroscopy with time of flight 2D mapping of superhydrophobic/superhydrophilic modified films with both positive (left and right) and negative (middle), (c) films designed with different patterns of superhydrophobic/superhydrophilic surfaces and highlighted with dyed water solutions. Reproduced with permission from Gou et al. [54]. ACS publications copyright $\odot 2016$ and (d) schematic of plausible chemical reactions to achieve superhydrophobic/superhydrophilic surfaces. Reproduced with permission from Fan et al. [55]. Elsevier copyright $\odot 2018$. 


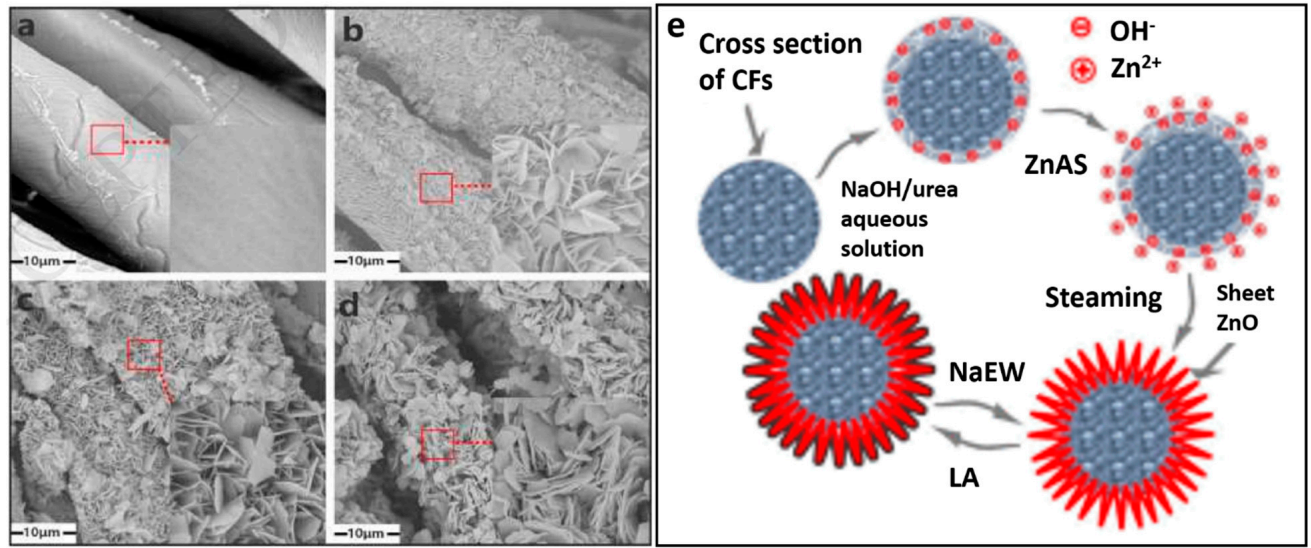

Figure 7. (a) unmodified, (b) ZnO modified, (c) ZnO-lauric acid modified, (d) ZnO-lauric acid-sodium hydroxide and ethyl alcohol aqueous solution modified cellulose fabric fibers and (e) diagrammatic representation of functionalization of reversible superhydrophobic/superhydrophilic cellulose fabric fiber. (NaEW—sodium hydroxide ethyl alcohol aqueous solution, LA—lauric acid). Reproduced with permission from Fan et al. [55]. Elsevier copyright (c) 2016.

The development of superhydrophobic surfaces has resulted in potential applications in water purification, medicine, biotechnological and materials interface. Modification of cellulose and its derivatives such as MCCs and CNCs have classically been modified using fluorinated moieties which typically exhibit hydrophobic characteristics especially to moisture. Though the technology of CNC is mostly at its infancy stage, the advancement in the use of CNCs in functional materials is a positive step towards moving away from dependence on petroleum-based materials. However, more research is needed in the modification techniques of CNCs to develop the use of fewer chemicals and steps. Reduction in modification steps will result to a lower cost of the end product in addition to the environmental benefits by cutting down on man hours and material cost of the added modificstion step(s).

\section{CNCs as Antimicrobial Agent Carriers}

The majority of the antimicrobial agents used are small in size thus there is always a probability for these active agents to leach out from the material (e.g., fabric, plastics, etc.) containing it [56]. Loss of antimicrobial agents to the fabric, skin and the environment contaminates the material and poses threat to health and environment [56]. The direct addition of antimicrobial agent also reduces the activity and efficiency as a result of leaching out and side reaction with food contents such as proteins and lipids [57]. Some antimicrobial chemical agents pose risk to human health and safety that led to the ban of a number of such agents (e.g., triclosan, iodine complex, phenol, triclocarban, etc.) that were commonly found in over the counter consumer products such as soap [58]. In other cases, the prevalence of antibiotic resistance as a result of microbial mutation and a decreasing effectiveness of antibiotics in treating common microbial infections resulted is another motivation for innovative ways of antimicrobial carrier development [59]. Thus, interest has grown in attaching or incorporating active antimicrobial agents to long chain polysaccharides and polymers especially CNCs.

Commonly used antimicrobial agents are halogens, phenols, silver nanoparticles and quaternary ammonium salts [60]. Transition metal oxides such as $\mathrm{Au}, \mathrm{Ag}$, $\mathrm{Ti}, \mathrm{Mg}, \mathrm{NO}, \mathrm{ZnO}, \mathrm{CuO}$ and $\mathrm{Fe}_{3} \mathrm{O}_{4}$ have antimicrobial properties as well [61]. Antimicrobial enzymes such as lactoperoxidase and lactoferrin and antimicrobial peptides magainins, cecropins, defensins are also often used [62].

Quaternary ammonium compounds (QACs) are positively charged, thus they absorb onto negatively charged microorganisms. They attack the surface cytoplasmic membrane once diffused through the cell wall. Due to the loss of essential constituents of the cell cytoplasm, it becomes difficult for the microorganisms to survive and they eventually die $[60,63]$. Thus, QACs are one of the most 
effective antimicrobial agents used. However, they are toxic to bacteria, pathogens (fungi and protozoa) as well as mammals which limit their applications.

Silver nanoparticles are preferred as antimicrobial agents due to the high activity against a wide range of microorganisms. Silver nanoparticles are active against yeast, fungi, viruses as well as both gram negative and gram positive viruses [64]. As the silver particles permeate through microorganisms they disrupt and restrict the respiratory function of the microorganisms, thereby resulting in death [65]. As the size of the silver particles decreases their efficacy increases due to increase in surface area, thus nanosized silver particles are preferred [66]. Silver particles inhibits the growth of Escherichia coli (E. Coli) and Staphylococcus aureus (S. aureus) [65,67]. Due to various uncertain health effect of silver nanoparticles, their use for food packaging in certain countries has not been accepted [64]. This has resulted in limited application and research especially in specific industries such as the food industry.

Triclosan is a synthetic biophenol $\left(2,4,4^{\prime}\right.$-trichloro-2'-hydroxydiphenyl ether) with excellent biocide activity. It is effective against both gram-positive and -negative bacteria, yeast and mold [68]. Hence, triclosan has a wide range of applications such as in soap, mouthwash, toys, packaging, textiles and kitchen utensils $[56,62,69]$. Use of triclosan is regulated by Environmental Protection Agency (EPA) due to its perceived toxicity and environmental risks, and as a result is its use in consumer products is limited [68].

Amongst naturally occurring antimicrobial agents, chitosan is derived from chitin and has gained a lot of popularity in commercial applications. Chitin is extracted from the exoskeleton of insects, as well as algae and fungi [56]. Chitosan is a polycationic polysaccharide with antimicrobial and antifungal activity $[70,71]$. Chitosan alters or forms a polymeric membrane on the surface of the cell restricting any nutrients from being absorbed, thus resulting in reduced growth and ultimate death of the cells [71,72]. Chitosan has been investigated for many applications such as packaging, drug delivery and other biomedical applications $[28,70,71]$. However, it is a slow acting antimicrobial agent due to its mechanism as stated previously, therefore, making it not as potent as other antimicrobial agents.

One of the main applications of antibacterial material is in the food packaging industry. Rather than just physical or moisture protection, successful packaging is one that inhibits the growth of microorganism in the food. Thus, active packaging is becoming popular in order to inhibit, reduce and kill microorganisms from the food surface or the surrounding adjacent to the packaging. Recently, consumer demand for low preservative food has increased. Thus, to maintain food quality under low preservation, active packaging can be very attractive. Active food packaging film can increase the product shelf life, maintain the nutritional value of food, provide microbial safety while restricting pathogenic growth. As a result, the need for active antimicrobial agent for food packaging has increased to maintain safe food quality [73].

As the demand for biodegradable and bioactive packaging gains popularity, research has been conducted to make active packaging film with Nisin, showed in Figure 8, as an antimicrobial agent. Nisin, 34-amino acid long bacteriocin, is active against many foodborne gram-positive bacterium such as Listeria monocytogens, Stephylococcus aureus and many more [74,75].

Nisin has been used to activate chitin to make an active packaging for pasteurized milk [76]. Additionally, it was reported that microbial growth on oyster and ground beef was delayed when nisin activated film was used for packaging [76]. Since nisin has demonstrated good antimicrobial activity, it was incorporated to polylactic acid-cellulose nanocrystal (PLA-CNC) composite [74]. Overall the nisin active PLA-CNC film contained all three essential packaging properties: antimicrobial activity, strength and biodegradability. Weishaupt et al. [75] reported the self-assembly of nanofibrilled cellulose-nisin biocomposite. TEMPO-oxidized nano-fibrillated cellulose containing carboxylic groups provided a negative surface for nisin to be adsorbed onto the surface [75]. The binding of nisin to nanocellulose was greatly affected by electrostatic interactions. However, at high salt concentration the binding capacity between nisin and nanocellulose was compromised [75]. Nisin bound nanocellulose was investigated against $S$. aureus and reduction in growth was observed [75]. Due to the beneficial 
properties observed, this biocomposite can be further enhanced to develop a promising application in biomedical industries.

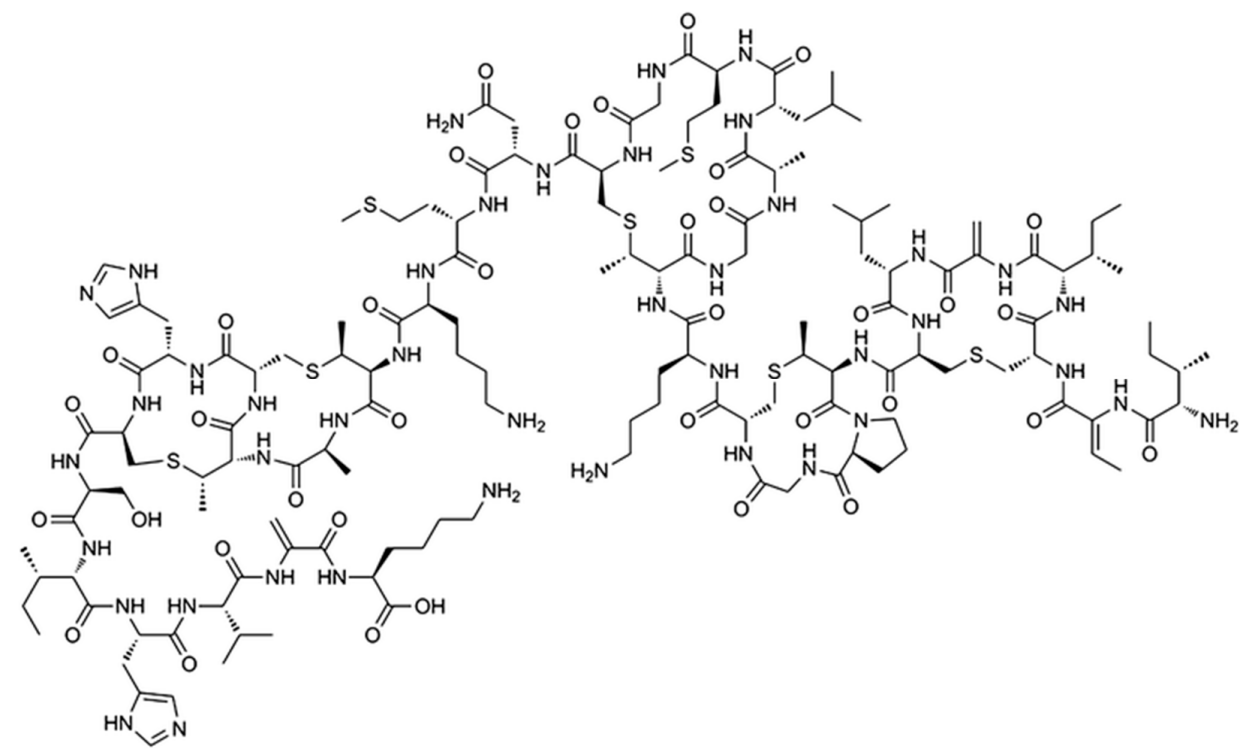

Figure 8. Chemical structure of Nisin. Reproduced with permission from Salmieri et al. [74]. Springer Nature copyright (C) 2014.

Silver nanoparticles are another commonly investigated antimicrobial agents incorporated with cellulose nanocrystals. Drogat at al. [65] reported the activity of silver nanoparticles-CNC composite against S. aureus (Gram positive) and E. coli (Gram negative). Oxidation of CNC was conducted via periodate $\left(\mathrm{NaIO}_{4}\right)$ to produce aldehyde, which was then used to reduce silver ions to $\mathrm{Ag}^{\mathrm{O}}$ to inhibit the growth of both the gram positive and negative bacteria [65]. Figure 9 shows the schematic of reaction of $\mathrm{CNC}$ with periodate to produce aldehyde followed by reduction of silver ion.
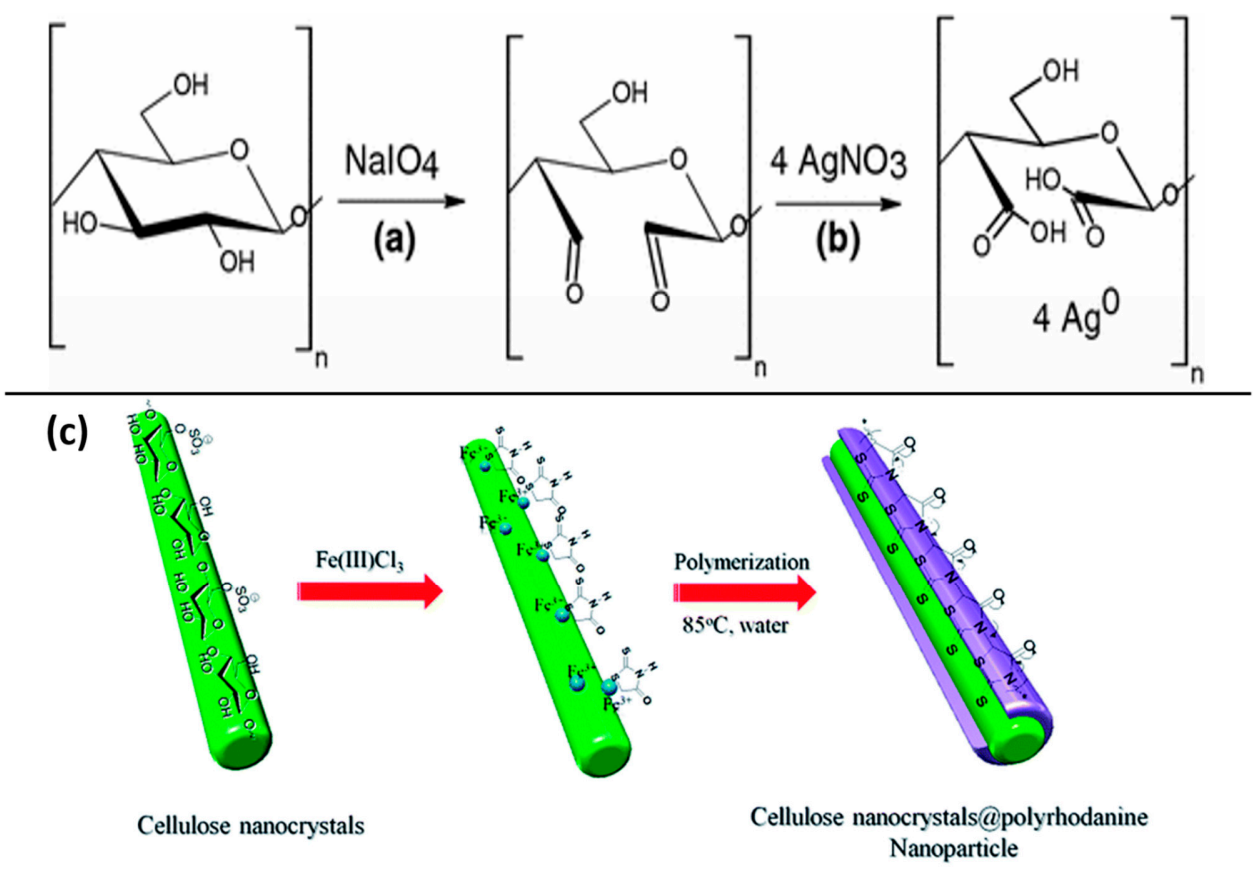

Figure 9. (a) Oxidation of $\mathrm{CNC}$, (b) Reduction of $\mathrm{Ag}^{+}$to $\mathrm{Ag}^{\mathrm{O}}$. Reproduced with permission from Drogat et al. [65]. Springer copyright (c) 2011 and (c) cellulose nanoparticles with polyrhodanine (CNC@PR) Fabrication. Reproduced with permission from Tang et al. [77]. RSC copyright @ 2014. 
Inhibited growth of bacteria suggests potential application of silver-CNC matrix for wound healing gels, antiseptic solution as well as other biomedical applications. Fortunati et al. also reports antimicrobial activity of PLA-CNC biocomposite containing $1 \mathrm{wt} . \%$ Ag nanoparticles against S. aureus and E. coli [64]. Higher activity was observed against E. coli than S. aureus due to greater toxicity of silver ions towards E. coli while significant amount of activity was also achieved for S. aureus $[64,78]$. PLA biocomposite with excellent antimicrobial activity against both gram-positive and gram-negative bacteria offers more opportunities for the development of active packaging for food, sanitary, and biomedical industries.

Amongst different structures for antimicrobial compounds, core-sheath structure of cellulose nanoparticles with polyrhodanine was reported by Tang et al. [79]. Cellulose nanoparticles with polyrhodanine (CNC@PR) showed antimicrobial activity against E. coli and B. Subtilis [79]. CNC@PR was synthesized with Fe (III) complex and ferric chloride to negatively charge the CNC surface. Fe (III) was used as an initiator and oxidant for the in situ polymerization of rhodanine on CNC $[77,79]$. Figure $9 \mathrm{c}$ shows the schematic of core-shell nanoparticles of $\mathrm{CNC}$ coated with polyrhodanine.

In academia and industry, antimicrobial materials are gaining a lot of interest due to the need to improve on the shelf life of food products. The application of antimicrobial materials is not only limited to food packaging but also a variety of other applications such as textile, coating, military and household equipment. High surface area and shorter diffusion path of nanofibers makes them an excellent choice for attaching antimicrobial molecules while also used as a reinforcing material for polymers as well [80]. Biomedical devices possessing antimicrobial-functionalized polymers can be proven very hygienic and efficient for health care purposes. Similarly, antimicrobial coatings can be used in hospital walls, kitchen counter tops and other pharmaceutical laboratories to maintain microbes-free environment. Household items, sanitary items for bathroom, kitchen utensil such as chopping board, kitchen towels, dish rack, toys for kids made from antimicrobial materials can promote healthy environment.

However, unlike other antimicrobial agent carriers, nanofibers can also provide mechanical strength which is desirable for most of the applications. This is currently an active research area with a focus on acquiring enhanced antimicrobial properties, cost optimization, and scale-up studies to commercialize these products.

\section{CNCs in Barrier Applications}

Limiting the effects of the environment on materials has long been a major concern in numerous industries. In the oil and gas industry where a network of pipping systems is a major vessel for transporting oil and chemicals, corrosion is a major problem and concern. In the marine industry, the exposure of vessels to sea water is constantly corroding and eroding the bottom of the vessels. Ultraviolet light exposure over time can alter the micromolecular properties of materials such as polymers, therefore changing the bulk properties. The use of CNCs in barrier applications are limited except for a few explorations in academia.

\subsection{UV Protection}

It is well known that over time when exposed to UV, the physical appearance of polyurethane (PU) starts to change; that results in yellowing of the material from the photochemical degradation of the surface molecules. In order to prevent or slow this process, research was carried out using CNCs as a UV stabilizer by Zhang et al. [81]. 3-Glycidyloxypropyl trimethoxysilane (GPTMS) was used to modify CNC at different concentrations. The GPTMS was hydrolyzed thereafter the CNC was added and allowed to react over time. Figure 10a shows the proposed reaction scheme during salinization and interaction between the modified CNC and PU. The modified CNC was then incorporated into the PU formulation and homogenized to disperse the modified CNC in the PU as shown in Figure 10b to create the PU/CNC composite. This composite was then exposed to a controlled UV radiation over time. The results from this study showed that the presence of a modified CNC in 
the PU drastically reduced the yellowing effect of the UV radiation with further reduction observed with increase in the concentration of the modified CNC. With the addition of $1.5 \%$ modified CNC, the anti-yellowing effect was increased by approximately $58 \%$ which demonstrated the effectiveness of $\mathrm{CNC}$ as an antiyellowing agent or a UV barrier agent as observed in Figure 10c. It was postulated that the addition of the modified CNC inhibited the photo degradation of the $\mathrm{CH}_{2}$ group while preventing the scissioning of the urethane group.
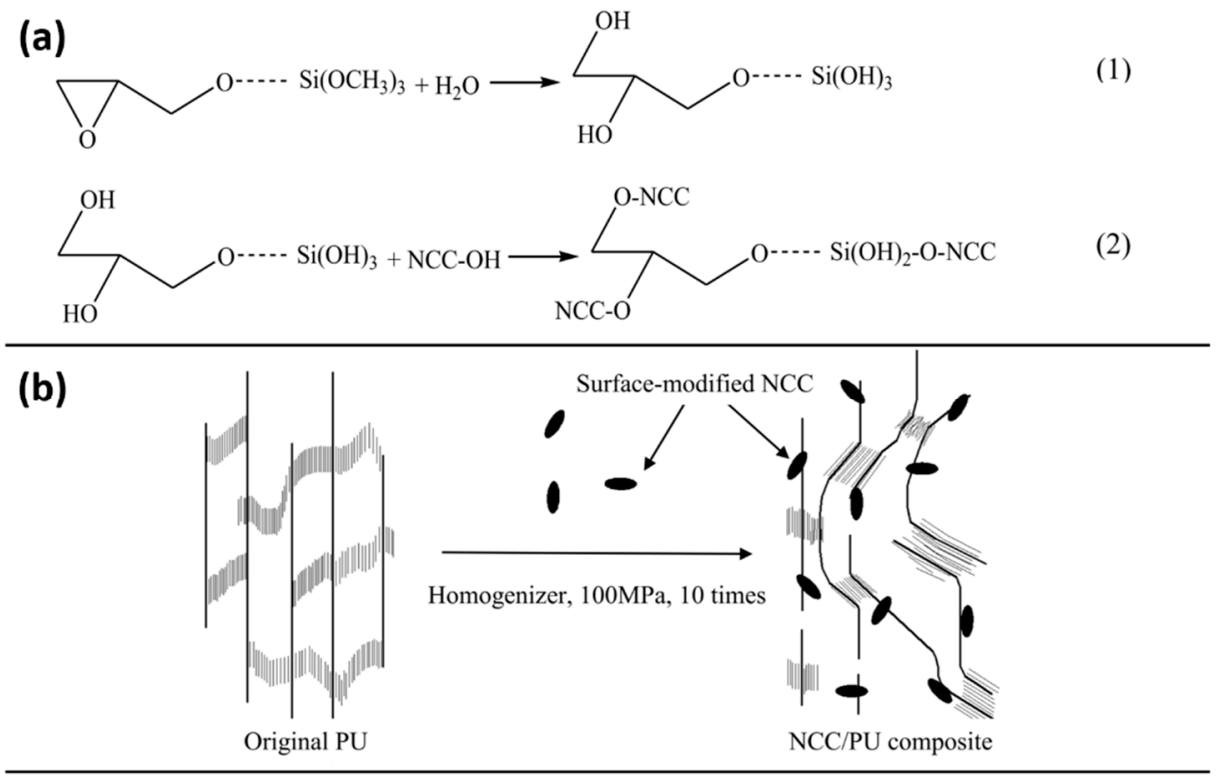

(c)

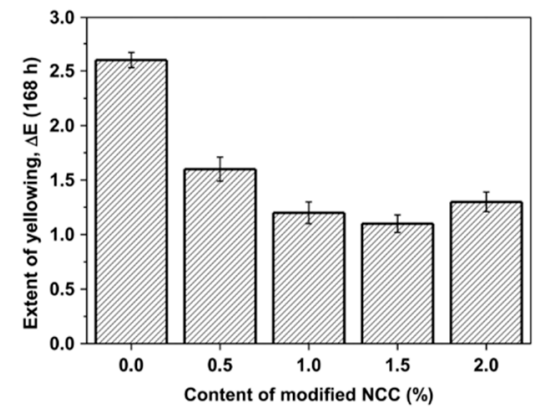

Figure 10. (a) reaction scheme for the modification of CNC using 3-Glycidyloxypropyl trimethoxysilane (GPTMS) (reaction scheme 1) and interaction between modified CNC and polyurethane (PU) (reaction scheme 2), (b) diagrammatic representation of the dispersion of modified CNC within the PU and (c) bar graph showing the effect of concentration of the modified CNC on the yellowing of PU upon exposure to UV radiation over a controlled period of time [81].

In another study, CNC was used as a bifunctional filler that provides reinforcement and UV barrier for poly vinyl alcohol polymer [81]. CNC pulp was oxidized using sodium metaperiodate and then reacted with sodium 4-amino-benzoate in an $\mathrm{HCl}$ solution to produce modified $\mathrm{CNC}$ with photo-active groups attached to it, which was further mechanically disintegrated to form $p$-aminobenzoic acid grafted CNC (PABA-CNC). This modified CNC was added to an aqueous polyvinyl alcohol (PVA) solution at different concentrations. This solution was further degassed and cast to form thin films which were then used for further tests. The results from the addition of PABA-CNC to PVA on the UV transmittance revealed that the presence of PABA-CNC in the PVA in comparison to neat PVA was significantly reduced and was also a function of the concentration of PABA-CNC within the PVA. Increasing the concentrations of PABA-CNC showed further reduction in UV transmittance with PVA films containing 0.5 and $10 \%$ PABA-CNC reducing the transmittance to 54 and $12 \%$, respectively in comparison to that of neat PVA film that exhibited $70 \%$ transmittance. Likewise, enhancement in 
the mechanical properties such as the tensile strength and modulus of the film was observed with PABA-CNC incorporation. This increase was also a function of the concentration of PABA-CNC. Similarly, ethyl cellulose nanoparticles (ECNPs) have been studied as a means to confine or protect UV filters which tend to create reactive oxygen species when exposed to UV due to photodegradation [81]. Typically, these filters are used for applications in cosmetics, such as sunscreens and can scavenge carcinogenic reactive oxygen species which can be harmful when they come in contact with the skin.

\subsection{Solvent and Chemical Protection}

Applications of surface coatings to help protect surface from the surrounding environment is a common practice in industry in many products today. Some of the applications include the use of paint on metals to prevent rust, application of clear coat epoxies on plastics and wood to prevent scratching and UV degradation and biodegradation, respectively. However, clear coat epoxies or paints for rust prevention do not always have good strength and chemical resistance. The characteristic properties of CNCs such as excellent strength and reinforcing capabilities at very low loadings due to its crystallinity and nano-size have lent its service in the application as a functional material in epoxy surface coatings of metals in a study by Ma et al. [82]. In this study, epoxy containing 1, 1.5 and $2 \mathrm{wt} . \%$ of $\mathrm{CNC}$ was thoroughly mixed using a glass rod and then sonicated to ensure proper dispersion and then brush coated onto mild steel in thin layers. The coated steel was allowed to dry and tested for its corrosive resistance using electrochemical impedance spectroscopy (EIS) by immersion in 3.5\% sodium chloride over a 30-day period. Similarly, the optical clarity or transmittance was tested using $\mathrm{UV}$ vis analysis to determine the effect of $\mathrm{CNC}$ in the epoxy coating. The results from the optical transmittance showed that with increasing CNC loading, the transmittance dropped to $20 \%$ for the coating containing $2 \mathrm{wt} . \%$. However, the coating containing $1 \mathrm{wt} . \% \mathrm{CNC}$ was observed to be very clear with a transmittance of $74 \%$. It was further observed that for all composites, the light drop-off transmittance was at approximately 300 to $350 \mathrm{~nm}$, which indicates high light absorption with no light reflections occurring in the UV range of 300 to $400 \mathrm{~nm}$. This indicates that when used in clear coat applications, this coating (especially at $1 \mathrm{wt} . \% \mathrm{CNC}$ ) can act to prevent $\mathrm{UV}$ degradation while still having high clarity. The corrosion test on the other hand, revealed that the presence of CNCs in the epoxy significantly increased the corrosion resistance of the epoxy coating. This could be because the CNC acted as a barrier to the ions from sodium hydroxide solution by creating a tortuous path. This resulted in preventing complete penetration of the coating, thereby protecting the mild steel surface. Only the unreinforced epoxy suffered penetration after 1 day of exposure. It was suggested that this was due to the $\mathrm{CNC}$ creating a longer path through which the solution had to travel in order to come in contact with the mild steel. Electrochemical analysis of the coatings through bode plots revealed that only the neat epoxy coating showed two-time constants. At day 30, only the unmodified epoxy continued to reveal two-time constants revealing the remarkable ability of the CNC to act as an anticorrosion agent. However, for the $2 \mathrm{wt} . \% \mathrm{CNC}$ loaded epoxy coating, as the test continued over the 30-day period, the appearance of a two-time constant slowly developed. This was attributed to the possible agglomeration of the CNCs within the epoxy which did not homogeneously disperse like those in the 1 and $1.5 \mathrm{wt} . \%$ loaded samples. Therefore, exposing unprotected regions within the epoxy to the solution allowed diffusion of the ions $\left(\mathrm{Na}^{+}\right.$and $\left.\mathrm{Cl}^{-}\right)$towards the mild steel that resulted in corrosion.

\section{Electrical Applications of CNCs}

Research into the development of functional applications of CNCs in electroactive materials such as electrical conductive materials, dielectric materials, microelectronics component etc. is an upcoming research area with some current materials such as starch [24], proteins and peptides [83] already being researched for similar applications. The interest for using CNCs in electrical applications is accrued mainly from its ease of modification, piezoelectric and dielectric properties, and sustainability attributes similar to other bio-derived materials. Csoka et al. asked the question of whether ultrathin 
films containing well aligned cellulose nanocrystals could exhibit piezoelectric effects stemming from the collective yield of the individual CNCs [84]. Ultrathin films containing different degrees of $\mathrm{CNC}$ alignment were produced according to a process well described by the authors in a different publication [85]. The displacement of the film was measured using atomic force microscopy in tapping mode while an electric field was applied to them. It was observed that the higher the degree of alignment, the greater the piezoelectric effect. Therefore, the piezoelectricity of the film was dependent on the orientation of the CNCs. This observation was deduced not only to the alignment of the CNCs but also due to dipolar orientation and the crystallinity of CNCs in the films. Figure 11a shows the schematic of Atomic Force Microscopy (AFM) in tapping mode with a diamond tip over ultrathin films containing aligned CNCs with an electric field applied across it while Figure 11b graphically demonstrates the effect of applied voltage to the thin films in response to the displacement of the CNCs. Given the result from this study, ultrathin films with various degrees of CNC alignment can result to different levels of electro-mechanical actuation, which could potentially be used in applications such as ultra-sensitive micro balances. For examples, having a high degree of CNC alignment and concentration can potentially result in ultra-sensitivity of applied forces.

CNCs are able to change polarization densities due to the high level of crystallinity. Likewise, its dielectric property allows it to be applied as a functional insulating material in different applications. However, moisture plays a huge role in determining the final dielectric property as it acts as a conductor of electricity when present in the CNC. For use in dielectric applications, the moisture levels should typically be $\sim 0.5 \%$ [86]. However, due to its hygroscopicity, it usually has a moisture level typically between $4-8 \%$. This range of moisture content stems from the source of the CNCs and highly dependent on the cellulose crystallinity as determined from studies on water sorption of cellulose $[87,88]$. Overall, the higher the crystallinity of the cellulose, the lower the moisture content will be and vice versa. Bras et al. studied the dielectric property of two nanocelluloses from wood (nanofibrillated cellulose, NFC) and algae (Cladophora cellulose) [86]. They found that the moisture sorption capability at low and high humidity was higher for NFC due to its lower crystallinity. However, contrary to the expectations that dielectric properties are highly related to crystallinity, a higher dielectric property was observed for NFC when compared to that of Cladophora cellulose. This was due to the high porosity of Cladophora cellulose which allowed for air entrapment, subsequently increasing its dielectric loss. It is apparent that CNCs do have excellent dielectric properties which can be harnessed for electrical insulation purpose such as in cable insulation, but the effectiveness of this property not only depends on the source but also on the morphological features [89]. It has also shown that paper from NFCs can be used to make dielectrics and not just as a substrate, with results comparable to wood, polymer and glass dielectric substrates [90].

(a)

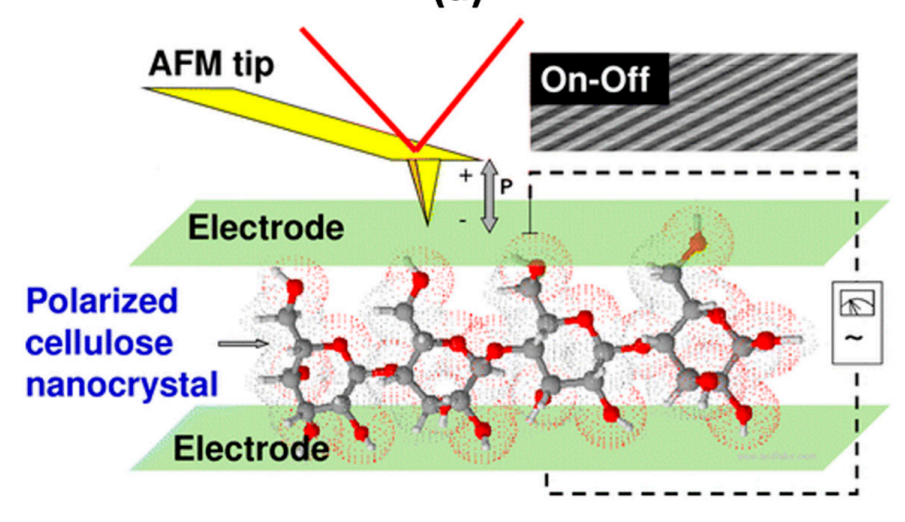

(b)

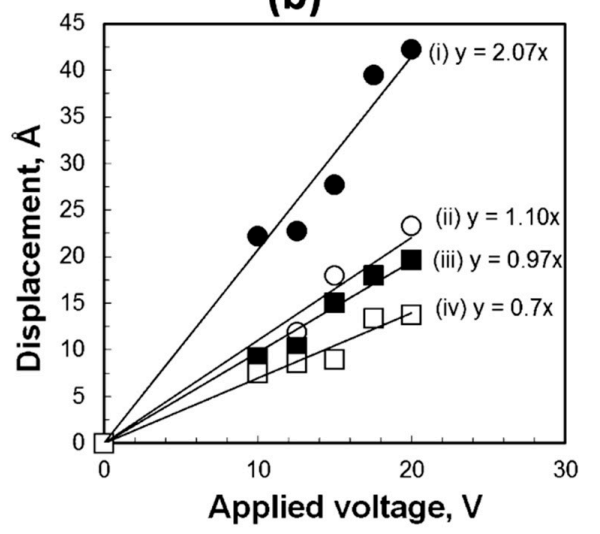

Figure 11. (a) Characterization of well aligned CNC ultrathin film for its dielectric property using Atomic Force Microscopy (AFM) in tapping mode and (b) effect of voltage on CNC displace (piezoelectric effect) [84]. 


\section{Other Applications of CNCs in Advanced Functional Materials}

Cellulose nanocrystals have gained a lot of interest as a renewable reinforcing filler due its biodegradability, low density, higher aspect ratio and excellent mechanical properties. CNCs are considered for a wide variety of applications since the surface hydroxyl groups of CNC can be functionalized as per requirement. CNCs obtained through sulfuric acid hydrolysis contain negative charge on the surface providing electrostatic repulsion between the CNCs. As a result, CNC can easily be dispersed in polar polymer matrices such as PVA. In the last two decades, applications of $\mathrm{CNC}$ have attracted academia and industrial researchers. Other than its use as a reinforcing agent, CNCs have demonstrated interesting potential for biomedical, antimicrobial, personal care and energy applications.

\subsection{Polymeric Reinforcement}

Cellulose nanocrystals are commonly used as a reinforcing filler in polymer matrices to enhance their strength. Traditional polymers alone lack strength required for most structural applications, thus requiring fillers to reinforce them. $\mathrm{CNC}$ as a bio-based material provides excellent reinforcement for polymers. Several studies have shown enhancement in both thermal and physical properties of polymers at very low concentrations of CNC incorporation due to its nano-size and ability to efficiently absorb stress from the matrix [21,91,92]. Bras et al. reported the reinforcing effect of CNC in rubber [93]. They found that $\mathrm{CNC}$ s were able to enhance the thermomechanical and mechanical properties of rubber. However, due to the hydrophilicity of the CNCs, the water absorption was increased. This study shows that CNCs can be used as polymer property enhancement when specific applications are targeted that do not expose the composites to moisture. Furthermore, reinforcing capabilities of CNC is also evident in cement as investigated by Cao et al. [94]. The water absorbing property of hydrophilic CNCs was an advantage in improving the flexural properties of cement paste. It was postulated that the hydration of the paste was improved when up to 0.2 vol.\% of CNC was added, subsequently leading to flexural strength increase of up to $30 \%$. These examples suggest that CNC can be the future of nano-polymer composite materials used for construction, automobile parts, furniture, and other industrial high-strength materials when targeted appropriately for specific materials.

A variety of polymers have been successfully grafted on CNC to modify its surface and obtain modified CNC with desirable properties. For instance, the use of hydrophobic polymer grafted CNC in non-polar polymers usually results in improved dispersion and interaction of the CNC with the polymer and enhances the strength of polymer composites made thereof. In other cases, the grafted polymer provides functionality attribute to the $\mathrm{CNC}$ that expands the application range of $\mathrm{CNC}$. Table 3 shows various polymers grafted to $\mathrm{CNC}$ and the achieved attribute as a result of the modification.

Table 3. Polymer Grafted Nanocellulose.

\begin{tabular}{|c|c|c|c|}
\hline POLYMER & $\begin{array}{l}\text { REACTION } \\
\text { MECHANISM }\end{array}$ & NOTES & REFERENCES \\
\hline POLY(4-VINYLPYRIDINE) (PVP) & $\begin{array}{l}\text { Ceric ion initiated radical } \\
\text { polymerization }\end{array}$ & $\begin{array}{l}\text { Thermal degradation temperature } \\
\text { improved by } 60^{\circ} \mathrm{C}\end{array}$ & [25] \\
\hline $\begin{array}{l}\text { POLYMETHYL METHACRYLATE } \\
\text { (PMMA) }\end{array}$ & $\begin{array}{l}\text { Atomic Transfer Radical } \\
\text { Polymerizstion (ATRP) }\end{array}$ & $\begin{array}{l}\text { Thermal stability decreased } \\
\quad\left(250^{\circ} \mathrm{C} \text { from } 295^{\circ} \mathrm{C}\right) \\
\text { Water contact angle increased by } 17^{\circ} \mathrm{C}\end{array}$ & [95] \\
\hline POLYETHYLENE GLYCOL (PEG) & Grafting to & $\begin{array}{l}\text { Thermal decomposition of grafted } \\
\text { CNC occurs at lower temperature }\end{array}$ & [96] \\
\hline POLY( $\varepsilon-C A P R O L A C T O N E)(P C L)$ & $\begin{array}{c}\text { Ring Opening } \\
\text { Polymerization (ROP) }\end{array}$ & $\begin{array}{l}\text { Addition of PCL grafted CNC into } \\
\text { PCL matrix improved young's } \\
\text { modulus from } 231 \text { to } 582 \mathrm{GPa} \\
\text { Elongation at break for same matrix } \\
\text { decreased drastically }\end{array}$ & [97] \\
\hline JEFFAMINES(POLYETHER AMINE) & Grafting-to & $\begin{array}{l}\text { Thermo-reversible aggregation } \\
\text { Polymer grafted CNC has lower } \\
\text { surface charge (zeta potential) }\end{array}$ & [98] \\
\hline
\end{tabular}


Table 3. Cont.

\begin{tabular}{cccc}
\hline POLYMER & $\begin{array}{c}\text { REACTION } \\
\text { MECHANISM }\end{array}$ & NOTES & REFERENCES \\
\hline POLYLACTIC ACID (PLA) & $\begin{array}{c}\text { Ring Opening } \\
\text { Polymerization (ROP) }\end{array}$ & $\begin{array}{c}\text { Well dispersed in non-polar solvent, } \\
\text { chloroform }\end{array}$ & [99] \\
\hline $\begin{array}{c}\text { POLYMETHYL ACRYLATE (PMA) } \\
\text { Pitroxide-mediated } \\
\text { Polymaerization (NMP) }\end{array}$ & $\begin{array}{c}\text { CNC grafted PMA was up to 1 wt.\% } \\
\text { soluble in THF and acetone } \\
\text { Grafted CNC was not dispersible in } \\
\text { water }\end{array}$ & [100] \\
(PTBA) & Grafting-to & $\begin{array}{c}\text { Stable suspension in chloroform, } \\
\text { toluene and acetone }\end{array}$ & {$[101]$} \\
\hline POLYSTYRENE (PS) & $\begin{array}{c}\text { Can absorb 50\% of } \\
\text { Atomic Transfer Radical } \\
\text { Polymerizstion (ATRP) }\end{array}$ & $\begin{array}{c}\text { 1,2,4-Trichlorobenzene (1,2,4-TCB), } \\
\text { organic pollutant } \\
\text { Water contact angle increased by 50 }{ }^{\circ} \mathrm{C}\end{array}$ & {$[102]$} \\
\hline
\end{tabular}

\subsection{Biomedical Applications}

Biomedical applications of $\mathrm{CNC}$ include the use of $\mathrm{CNC}$ for medical devices, bioimaging, wound healing, scaffolds for tissue engineering and controlled drug delivery [103]. A lot of interest in biomedical application of CNC based materials stems from its biodegradability, biocompatibility, lower toxicity and excellent mechanical properties. Dong and Roman investigated fluorescently labeled CNC for bioimaging applications [104]. In this study, CNC was conjugated with fluorescein- $5^{\prime}$-isothiocyanate using epichlorohydrin to study its biodistribution and in vivo interaction using the fluorescence labelling, which can be beneficial in many biomedical applications. This study showed that the modified CNC can be used to study interacion with cells. The authors also acknowledged that the developed functionalized CNC was being further used to study interactions with mammalian cells in another collaborative study. Drug delivery carriers can sometimes cause biological systems such as the human body to have immunological responses. Therefore, it is important that drug delivery systems do not cause adverse effects while performing their functions. A study on the use of CNCs as carriers for cyclodextrin showed that CNC was efficient as a drug delivery agent as well as having no adverse effects; immunological responses were observed to be negligible such as the secretion of pro-inflammatory cytokine, interleukin $1 \beta$ (IL-1 $\beta$ ), by enzyme-linked immunosorbent assay (ELISA) and mitochondria-derived reactive oxygen species (ROS) using fluorescence cell imaging [105].

$\mathrm{CNC}$ is extensively studied for tissue engineering where a scaffold device is used for self-healing and regeneration. In order to obtain an enhanced performance appropriate material selection for scaffold is very crucial. Mechanical, physical and biological properties play a vital role in elevated performance and suitable mechanical integration [106]. Thus, properties such as surface roughness, topology, porosity, pore size, surface area to volume ratio must be considered [107]. Moreover, degradation rate of biodegradable material is very important so that the healthy tissue can be restored while scaffold material gets absorbed. In order to achieve both the mechanical and biological properties unfilled polymer materials cannot be used in most cases. Thus, nanofillers are incorporated to form a nanocomposite that provides functional benefits such as mechanical strength, electrical conductivity, adhesiveness and ability to self-assemble [106,107]. A review on CNC-based biomaterial for tissue engineering by Domingues et al. [107] extensively describes the use of CNC-PLA composite material for tissue engineering to fulfill aforementioned requirements for biomedical scaffolding applications. Along with other biomedical, and pharmaceutical products, CNC can open new doors to new personal care products $[108,109]$.

\subsection{Energy Applications}

Energy application of $\mathrm{CNC}$ includes the use of cellulose-based composites for energy storage. With growing environmental concerns, interest has grown in making renewable energy source more efficient and feasible. An attempt to produce recyclable solar cell from cellulose nanocrystal by Zhou et al. is a contribution towards the same initiative [110]. While taking advantage of the 
excellent mechanical properties of $\mathrm{CNC}$ and silver, a semitransparent electrode recyclable solar cell was fabricated [110]. However, further improvements were needed to obtain efficient and desirable performance. Kim et al. reported other energy applications of cellulose based materials such as energy harvester, display devices, actuators and paper transistors [111]. Excellent mechanical and biocompatible properties of $\mathrm{CNC}$ as well as its ease of functionalization gives it the potential to provide environmentally friendly and sustainable technologies.

\subsection{Smart and Responsive Materials}

The application of smart responsive materials has increased in recent times. Smart responsive materials adapt to external environment and provide response. Changes in stimulus such as exposure to light, heat, chemicals, magnetic fields can be used to generate mechanically adaptive, stimuli-responsive materials. Nanocomposite can respond to exposure to external stimuli in various ways such as swell or shrink, assemble or dissemble or prompts for separation [112]. These changes generated as a response to stimuli variations can be used to develop a smart material. CNC can be used as a stimuli-responsive material for sensors and other applications. CNC displays responsiveness towards $\mathrm{pH}$, light, moisture, heat, chemical and magnetic fields, which adds the stimuli-responsiveness functionality along with reinforcing capabilities. Changes in $\mathrm{pH}$ corresponds with changes in rheological properties of CNC composites [113]. Way et al. [113] synthesized carboxylated and amine functionalized $\mathrm{CNC}$ to investigate $\mathrm{pH}$ responsiveness. By altering the surface chemistry of $\mathrm{CNC}$, the nanocomposites can be reprogrammed to develop various mechanically adaptable materials.

Since modified CNC has the ability to generate a response to changes in external stimuli, they can be readily used in sensing applications. Smart CNC-based sensors can be designed for moisture, ions, organic vapors, and biological species sensing applications. Humidity sensor designed by Kafy et al. [114] is made from CNC-graphene oxide (GO) composite. CNC and graphene both are hydrophilic with higher water uptake capacity. CNC-GO film displayed even increased water uptake capacity which is desirable for moisture sensitivity [114]. The sensing film did not compromise its performance with temperature change, demonstrating practical use of humidity sensor [114]. Similarly, CNC can be functionalized to make gas sensing material which can detect other organic and toxic vapors. Moreover, CNC based sensing material can also be used to detect ionic species. $\mathrm{CNC}$ containing pyrene was synthesized to detect ferric $\left(\mathrm{Fe}^{3+}\right)$ ions [115]. This concept can be further explored to design a sensing material for different ions, chemical and biological molecules. Other smart sensors made from CNC include proximity sensor and strain sensor by Sadasivuni et al. [116] and Wang et al. [117] respectively.

Hydrophilicity of CNC can be used to generate water-responsive mechanically adaptive polymer matrix. For instance, Pratheep et al. [118] designed a water sensitive styrene-butadiene-rubber (SBR) and CNC nanocomposite. First of all, the reinforcing capabilities was proven since the modulus of pure SBR (3 MPa) was improved significantly (to $740 \mathrm{MPa}$ ) [118]. CNC aids as a hydrophilic channel in a hydrophobic matrix for water uptake. CNC is used to generate water-responsive mechanically adaptive material because upon water swelling, CNC network is disrupted to cause reduction in modulus $[118,119]$. Thus physiological variation can lead to change in mechanical properties to design a mechanically adaptive materials [118]. Mendez et al. [119] also used the water-responsive ability of $\mathrm{CNC}$ to design a smart polyurethane-CNC nanocomposite, which displayed water activated shape memory effect.

Similar to $\mathrm{pH}$ and moisture response adaptive materials, thermal and photonic responsive materials were also generated. Cellulose nanocrystals grafted with thermoresponsive brushes of poly (N-isopropylacrylamide) has also been investigated [120-122]. Novel and effective drug therapies have also been investigated to develop a controlled drug delivery method. Controlled drug release provides advantages such as maintaining required therapeutic concentration, localized drug delivery and improve patient compliance, however these novel techniques are yet to be explored to develop drug delivery materials sensitive to physiological changes [123]. Thus, stimuli-responsive polymeric 
drug delivery processes are typically used for controlled drug delivery. $\mathrm{CNCs}$, being biocompatible and biodegradable polymer, can be functionalized to develop smart material that offers a great potential in targeted, controlled drug delivery systems $[111,123]$.

The study of CNC for smart electronic application has also gained enormous interest. In the Review of Nanocellulose for Sustainable Future Material, Kim et al. [111] has reported various use of CNC based material in energy and electronics applications. Electroactive paper (EAPap), which functions based on two principles i.e., ion migration and piezoelectric effect has application in sensors, actuators, biomimetic robots, and other haptic technology [111,112].

\section{Challenges, Future Trends and Conclusions}

Although CNCs have many desirable properties, their high hygroscopicity, hydrophilicity and tendency to aggregate and form bundles, can drastically restrict their applications [3]. These characteristics lead to the formation of flake-like agglomerates in polymer composites due to surface area and volume effects and the strong intermolecular hydrogen bonding between $\mathrm{CNC}$ particles [64]. Aggregation of CNC particles can significantly hinder the performance of the matrices. This suggests that the issue with agglomeration of CNCs must be resolved to achieve its touted reinforcing performance when used as a filler in polymeric and other applications. However, its hydrophilic nature can also play a positive role in enhancing hybrid systems such as cement paste. Therefore, the inherent properties of CNCs are typically deemed as negative can be advantageous and geared towards specific applications. However, the properties can be modified to reduce or completely eliminate its effects as a durable functional material. During CNC modification, it is important to limit the modification only to its surface so as to preserve its structural and morphological integrity [36]. However, the reality is that most CNC modifications involve aggressive oxidization to increase the concentration of hydroxyl groups on its surface to be used as anchor points for further modifications. This usually effects its structural integrity and crystallinity, which could subsequently alter its mechanical properties. Therefore, new and less aggressive modification processed and/or chemicals need to be developed to achieve the same level of modifications as currently used.

Though CNCs have excellent thermal stability in comparison to other bio-based fibers, long term durability of products is of concern when it is incorporated or used as a functional material. Moreover, commercial products intending to apply $\mathrm{CNCs}$ in functional applications need multiple and abundant sources. Currently, the majority of CNC production is limited to North America and to some Scandinavian countries (e.g., Sweden, Finland) [124]. Expected rise in CNC production in the future will definitely give raise to the application on an industrial scale [18].

The versality of CNC functionalization can be the future of sustainable, biocompatible, and biodegradable material for a variety of applications, especially with the current environmental concerns such as climate change from greenhouse gases from production and use of petroleum derived materials. Due to its abundance across the globe, bio-renewability and the fast-growing technologies on its production, CNCs are becoming the focus of product development and research as observed from the numerous researches published on CNCs in recent years. Therefore, it is foreseeable that in the nearest future, CNCs will be widely and extensively found in the medical, electronics, oil and gas, biotechnology and food industries just to mention a few. CNCs have also been shown to be a viable option to potential replace synthetic materials for functional applications in various industries. As CNCs continue to gain great attention from researchers all over the world, more understanding and applications with improved technology towards production will rapidly be developed thereby taking CNCs from lab to industrial scale.

Author Contributions: Conceptualization, P.P., E.O., T.M.; writing-original draft preparation, P.P. and E.O; writing-review and editing, P.P., E.O., T.M; supervision, T.M.; project administration, T.M.; funding acquisition, T.M.

Funding: The authors acknowledge the financial support of InnoTech Alberta through the CNC Challenge grant.

Acknowledgments: We thank our colleagues in the same group for the insightful discussions on the subject matter. 
Conflicts of Interest: The authors declare no conflict of interest.

\section{References}

1. Habibi, Y.; Lucia, L.A.; Rojas, O.J. Cellulose Nanocrystals: Chemistry, Self-Assembly, and Applications. Chem. Rev. 2010, 110, 3479-3500. [CrossRef] [PubMed]

2. Bettaieb, F.; Khiari, R.; Dufresne, A.; Mhenni, M.F.; Belgacem, M.N. Mechanical and thermal properties of Posidonia oceanica cellulose nanocrystal reinforced polymer. Carbohydr. Polym. 2015, 123, 99-104. [CrossRef]

3. Lu, P.; Hsieh, Y.-L. Preparation and properties of cellulose nanocrystals: Rods, spheres, and network. Carbohydr. Polym. 2010, 82, 329-336. [CrossRef]

4. Eyley, S.; Thielemans, W. Surface modification of cellulose nanocrystals. Nanoscale 2014, 6, 7764-7779. [CrossRef] [PubMed]

5. Wang, B.; Sain, M.; Oksman, K. Study of Structural Morphology of Hemp Fiber from the Micro to the Nanoscale. Appl. Compos. Mater. 2007, 14, 89-103. [CrossRef]

6. Ogunsona, E.O.; Misra, M.; Mohanty, A.K. Accelerated hydrothermal aging of biocarbon reinforced nylon biocomposites. Polym. Degrad. Stab. 2017, 139, 76-88. [CrossRef]

7. Ogunsona, E.O.; Misra, M.; Mohanty, A.K. Sustainable biocomposites from biobased polyamide 6,10 and biocarbon from pyrolyzed miscanthus fibers. J. Appl. Polym. Sci. 2017, 134. [CrossRef]

8. Ogunsona, E.O.; Misra, M.; Mohanty, A.K. Influence of epoxidized natural rubber on the phase structure and toughening behavior of biocarbon reinforced nylon 6 biocomposites. RSC Adv. 2017, 7, 8727-8739. [CrossRef]

9. Ogunsona, E.O.; Misra, M.; Mohanty, A.K. Effects of Accelerated Aging on the Flammability of Polypropylene Based Biocomposites. In Proceedings of the ANTEC Conference Proceedings, Orlando, FL, USA, 23-25 March 2015.

10. Ogunsona, E.O.; Codou, A.; Misra, M.; Mohanty, A.K. Thermally Stable Pyrolytic Biocarbon as an Effective and Sustainable Reinforcing Filler for Polyamide Bio-composites Fabrication. J. Polym. Environ. 2018. [CrossRef]

11. Ogunsona, E.O.; Misra, M.; Mohanty, A.K. Impact of interfacial adhesion on the microstructure and property variations of biocarbons reinforced nylon 6 biocomposites. Compos. Part A Appl. Sci. Manuf. 2017, 98, 32-44. [CrossRef]

12. Ilyas, R.A.; Sapuan, S.M.; Sanyang, M.L.; Ishak, M.R.; Zainudin, E.S. Nanocrystalline Cellulose as Reinforcement for Polymeric Matrix Nanocomposites and its Potential Applications: A Review. Curr. Anal. Chem. 2018, 14, 203-225. [CrossRef]

13. Shojaeiarani, J.; Bajwa, D.S.; Stark, N.M. Green esterification: A new approach to improve thermal and mechanical properties of poly(lactic acid) composites reinforced by cellulose nanocrystals. J. Appl. Polym. Sci. 2018, 135, 46468. [CrossRef]

14. Sobolčiak, P.; Tanvir, A.; Popelka, A.; Moffat, J.; Mahmoud, K.A.; Krupa, I. The preparation, properties and applications of electrospun co-polyamide 6,12 membranes modified by cellulose nanocrystals. Mater. Des. 2017, 132, 314-323. [CrossRef]

15. Rahimi, S.K.; Otaigbe, J.U. The effects of the interface on microstructure and rheo-mechanical properties of polyamide 6/cellulose nanocrystal nanocomposites prepared by in-situ ring-opening polymerization and subsequent melt extrusion. Polymer 2017, 127, 269-285. [CrossRef]

16. Inai, N.H.; Lewandowska, A.E.; Ghita, O.R.; Eichhorn, S.J. Interfaces in polyethylene oxide modified cellulose nanocrystal - polyethylene matrix composites. Compos. Sci. Technol. 2018, 154, 128-135. [CrossRef]

17. Orts, W.J.; Shey, J.; Imam, S.H.; Glenn, G.M.; Guttman, M.E.; Revol, J.-F. Application of Cellulose Microfibrils in Polymer Nanocomposites. J. Polym. Environ. 2005, 13, 301-306. [CrossRef]

18. Moon, R.J.; Martini, A.; Nairn, J.; Simonsen, J.; Youngblood, J. Cellulose nanomaterials review: Structure, properties and nanocomposites. Chem. Soc. Rev. 2011, 40, 3941-3994. [CrossRef] [PubMed]

19. Lee, K.-Y.; Aitomäki, Y.; Berglund, L.A.; Oksman, K.; Bismarck, A. On the use of nanocellulose as reinforcement in polymer matrix composites. Compos. Sci. Technol. 2014, 105, 15-27. [CrossRef]

20. Jonoobi, M.; Oladi, R.; Davoudpour, Y.; Oksman, K.; Dufresne, A.; Hamzeh, Y.; Davoodi, R. Different preparation methods and properties of nanostructured cellulose from various natural resources and residues: A review. Cellulose 2015, 22, 935-969. [CrossRef] 
21. Xu, X.; Liu, F.; Jiang, L.; Zhu, J.Y.; Haagenson, D.; Wiesenborn, D.P. Cellulose Nanocrystals vs. Cellulose Nanofibrils: A Comparative Study on Their Microstructures and Effects as Polymer Reinforcing Agents. ACS Appl. Mater. Interfaces 2013, 5, 2999-3009. [CrossRef]

22. Mekonnen, T.H.; Mussone, P.G.; Choi, P.; Bressler, D.C. Development of Proteinaceous Plywood Adhesive and Optimization of Its Lap Shear Strength. Macromol. Mater. Eng. 2015, 300, 198-209. [CrossRef]

23. Ojogbo, E.; Blanchard, R.; Mekonnen, T. Hydrophobic and Melt Processable Starch-Laurate Esters: Synthesis, Structure-Property Correlations. J. Polym. Sci. Part A Polym. Chem. 2018, 56, 2611-2622. [CrossRef]

24. Ogunsona, E.; Ojogbo, E.; Mekonnen, T. Advanced material applications of starch and its derivatives. Eur. Polym. J. 2018, 108, 570-581. [CrossRef]

25. Kan, K.H.M.; Li, J.; Wijesekera, K.; Cranston, E.D. Polymer-Grafted Cellulose Nanocrystals as pH-Responsive Reversible Flocculants. Biomacromolecules 2013, 14, 3130-3139. [CrossRef] [PubMed]

26. Brown, A.J. XIX.-The chemical action of pure cultivations of bacterium aceti. J. Chem. Soc. Trans. 1886, 49, 172-187. [CrossRef]

27. Kim, N.; Retsina, T. Innovative nanocellulose process breaks the cost barrier. TAPPI J. 2014, 13, 19-23.

28. Akhlaghi, S.P.; Berry, R.C.; Tam, K.C. Surface modification of cellulose nanocrystal with chitosan oligosaccharide for drug delivery applications. Cellulose 2013, 20, 1747-1764. [CrossRef]

29. Peng, B.L.; Dhar, N.; Liu, H.L.; Tam, K.C. Chemistry and applications of nanocrystalline cellulose and its derivatives: A nanotechnology perspective. Can. J. Chem. Eng. 2011, 89, 1191-1206. [CrossRef]

30. Chen, L.; Wang, Q.; Hirth, K.; Baez, C.; Agarwal, U.P.; Zhu, J.Y. Tailoring the yield and characteristics of wood cellulose nanocrystals (CNC) using concentrated acid hydrolysis. Cellulose 2015, 22, 1753-1762. [CrossRef]

31. Silvério, H.A.; Flauzino Neto, W.P.; Dantas, N.O.; Pasquini, D. Extraction and characterization of cellulose nanocrystals from corncob for application as reinforcing agent in nanocomposites. Ind. Crops Prod. 2013, 44, 427-436. [CrossRef]

32. Kalashnikova, I.; Bizot, H.; Bertoncini, P.; Cathala, B.; Capron, I. Cellulosic nanorods of various aspect ratios for oil in water Pickering emulsions. Soft Matter 2013, 9, 952-959. [CrossRef]

33. Cao, X.; Dong, H.; Li, C.M. New nanocomposite materials reinforced with flax cellulose nanocrystals in waterborne polyurethane. Biomacromolecules 2007, 8, 899-904. [CrossRef]

34. Habibi, Y.; Foulon, L.; Aguié-Béghin, V.; Molinari, M.; Douillard, R. Langmuir-Blodgett films of cellulose nanocrystals: Preparation and characterization. J. Colloid Interface Sci. 2007, 316, 388-397. [CrossRef] [PubMed]

35. Garcia de Rodriguez, N.L.; Thielemans, W.; Dufresne, A. Sisal cellulose whiskers reinforced polyvinyl acetate nanocomposites. Cellulose 2006, 13, 261-270. [CrossRef]

36. Kaboorani, A.; Riedl, B. Surface modification of cellulose nanocrystals (CNC) by a cationic surfactant. Ind. Crops Prod. 2015, 65, 45-55. [CrossRef]

37. Grishkewich, N.; Mohammed, N.; Tang, J.; Tam, K.C. Recent advances in the application of cellulose nanocrystals. Curr. Opin. Colloid Interface Sci. 2017, 29, 32-45. [CrossRef]

38. Bravo, J.; Zhai, L.; Wu, Z.; Cohen, R.E.; Rubner, M.F. Transparent superhydrophobic films based on silica nanoparticles. Langmuir 2007, 23, 7293-7298. [CrossRef] [PubMed]

39. Song, J.; Rojas, O.J. Approaching super-hydrophobicity from cellulosic materials: A Review. Pap. Chem. Nord. Pulp Pap. Res. J. 2100, 28, 216-238. [CrossRef]

40. Li, S.; Xie, H.; Zhang, S.; Wang, X. Facile transformation of hydrophilic cellulose into superhydrophobic cellulose. Chem. Commun. 2007, 4857-4859. [CrossRef]

41. Teisala, H.; Tuominen, M.; Kuusipalo, J. Superhydrophobic Coatings on Cellulose-Based Materials: Fabrication, Properties, and Applications. Adv. Mater. Interfaces 2014, 1, 1300026. [CrossRef]

42. Manca, M.; Cannavale, A.; De Marco, L.; Aricò, A.S.; Cingolani, R.; Gigli, G. Durable superhydrophobic and antireflective surfaces by trimethylsilanized silica nanoparticles-based sol-gel processing. Langmuir 2009, 25, 6357-6362. [CrossRef] [PubMed]

43. Salam, A.; Lucia, L.A.; Jameel, H. Fluorine-based surface decorated cellulose nanocrystals as potential hydrophobic and oleophobic materials. Cellulose 2015, 22, 397-406. [CrossRef]

44. Shang, W.; Huang, J.; Luo, H.; Chang, P.R.; Feng, J.; Xie, G. Hydrophobic modification of cellulose nanocrystal via covalently grafting of castor oil. Cellulose 2013, 20, 179-190. [CrossRef]

45. Salajková, M.; Berglund, L.A.; Zhou, Q. Hydrophobic cellulose nanocrystals modified with quaternary ammonium salts. J. Mater. Chem. 2012, 22, 19798-19805. [CrossRef] 
46. Yu, M.; Gu, G.; Meng, W.-D.; Qing, F.-L. Superhydrophobic cotton fabric coating based on a complex layer of silica nanoparticles and perfluorooctylated quaternary ammonium silane coupling agent. Appl. Surf. Sci. 2007, 253, 3669-3673. [CrossRef]

47. Ogihara, H.; Xie, J.; Okagaki, J.; Saji, T. Simple Method for Preparing Superhydrophobic Paper: Spray-Deposited Hydrophobic Silica Nanoparticle Coatings Exhibit High Water-Repellency and Transparency. Langmuir 2012, 28, 4605-4608. [CrossRef] [PubMed]

48. Samyn, P. Wetting and hydrophobic modification of cellulose surfaces for paper applications. J. Mater. Sci. 2013, 48, 6455-6498. [CrossRef]

49. Bae, G.Y.; Min, B.G.; Jeong, Y.G.; Lee, S.C.; Jang, J.H.; Koo, G.H. Superhydrophobicity of cotton fabrics treated with silica nanoparticles and water-repellent agent. J. Colloid Interface Sci. 2009, 337, 170-175. [CrossRef]

50. Xue, C.-H.; Jia, S.-T.; Zhang, J.; Ma, J.-Z. Large-area fabrication of superhydrophobic surfaces for practical applications: An overview. Sci. Technol. Adv. Mater. 2010, 11, 033002. [CrossRef]

51. Zhou, S.; Liu, P.; Wang, M.; Zhao, H.; Yang, J.; Xu, F. Sustainable, Reusable, and Superhydrophobic Aerogels from Microfibrillated Cellulose for Highly Effective Oil/Water Separation. ACS Sustain. Chem. Eng. 2016, 4, 6409-6416. [CrossRef]

52. Cheng, Q.-Y.; Guan, C.-S.; Wang, M.; Li, Y.-D.; Zeng, J.-B. Cellulose nanocrystal coated cotton fabric with superhydrophobicity for efficient oil/water separation. Carbohydr. Polym. 2018, 199, 390-396. [CrossRef] [PubMed]

53. Huang, J.; Wang, S.; Lyu, S.; Fu, F. Preparation of a robust cellulose nanocrystal superhydrophobic coating for self-cleaning and oil-water separation only by spraying. Ind. Crops Prod. 2018, 122, 438-447. [CrossRef]

54. Guo, J.; Fang, W.; Welle, A.; Feng, W.; Filpponen, I.; Rojas, O.J.; Levkin, P.A. Superhydrophobic and Slippery Lubricant-Infused Flexible Transparent Nanocellulose Films by Photoinduced Thiol-Ene Functionalization. ACS Appl. Mater. Interfaces 2016, 8, 34115-34122. [CrossRef] [PubMed]

55. Fan, T.; Qian, Q.; Hou, Z.; Liu, Y.; Lu, M. Preparation of smart and reversible wettability cellulose fabrics for oil/water separation using a facile and economical method. Carbohydr. Polym. 2018, 200, 63-71. [CrossRef] [PubMed]

56. Varesano, A.; Vineis, C.; Aluigi, A.; Rombaldoni, F. Antimicrobial polymers for textile products. Sci. Against Microb. Pathog. Commun. Curr. Res. Technol. Adv. 2011. Available online: http://www.formatex.info/ microbiology3/book/99-110.pdf (accessed on 24 November 2018).

57. Mauriello, G.; De Luca, E.; La Storia, A.; Villani, F.; Ercolini, D. Antimicrobial activity of a nisin-activated plastic film for food packaging. Lett. Appl. Microbiol. 2005, 41, 464-469. [CrossRef] [PubMed]

58. Kodjak, A. FDA Bans 19 Chemicals Used in Antibacterial; Your Health: Salt Lake City, UT, USA, 2016.

59. Laxminarayan, R.; Duse, A.; Wattal, C.; Zaidi, A.K.M.; Wertheim, H.F.L.; Sumpradit, N.; Vlieghe, E.; Hara, G.L.; Gould, I.M.; Goossens, H.; et al. Antibiotic resistance-The need for global solutions. Lancet Infect. Dis. 2013, 13, 1057-1098. [CrossRef]

60. Roy, D.; Knapp, J.S.; Guthrie, J.T.; Perrier, S. Antibacterial Cellulose Fiber via RAFT Surface Graft Polymerization. Biomacromolecules 2008, 9, 91-99. [CrossRef]

61. Wang, L.; Hu, C.; Shao, L. The antimicrobial activity of nanoparticles: Present situation and prospects for the future. Int. J. Nanomed. 2017, 12, 1227-1249. [CrossRef]

62. Appendini, P.; Hotchkiss, J.H. Review of antimicrobial food packaging. Innov. Food Sci. Emerg. Technol. 2002, 3, 113-126. [CrossRef]

63. Huang, K.-S.; Yang, C.-H.; Huang, S.-L.; Chen, C.-Y.; Lu, Y.-Y.; Lin, Y.-S. Recent Advances in Antimicrobial Polymers: A Mini-Review. Int. J. Mol. Sci. 2016, 17, 1578. [CrossRef]

64. Fortunati, E.; Rinaldi, S.; Peltzer, M.; Bloise, N.; Visai, L.; Armentano, I.; Jiménez, A.; Latterini, L.; Kenny, J.M. Nano-biocomposite films with modified cellulose nanocrystals and synthesized silver nanoparticles. Carbohydr. Polym. 2014, 101, 1122-1133. [CrossRef] [PubMed]

65. Drogat, N.; Granet, R.; Sol, V.; Memmi, A.; Saad, N.; Klein Koerkamp, C.; Bressollier, P.; Krausz, P. Antimicrobial silver nanoparticles generated on cellulose nanocrystals. J. Nanopart. Res. 2011, 13, 1557-1562. [CrossRef]

66. Lala, N.L.; Ramaseshan, R.; Bojun, L.; Sundarrajan, S.; Barhate, R.S.; Ying-jun, L.; Ramakrishna, S. Fabrication of nanofibers with antimicrobial functionality used as filters: Protection against bacterial contaminants. Biotechnol. Bioeng. 2007, 97, 1357-1365. [CrossRef] [PubMed] 
67. Lam, E.; Male, K.B.; Chong, J.H.; Leung, A.C.W.; Luong, J.H.T. Applications of functionalized and nanoparticle-modified nanocrystalline cellulose. Trends Biotechnol. 2012, 30, 283-290. [CrossRef] [PubMed]

68. Ramos, A.I.; Braga, T.M.; Fernandes, J.A.; Silva, P.; Ribeiro-Claro, P.J.; Almeida Paz, F.A.; de Fátima Silva Lopes, M.; Braga, S.S. Analysis of the microcrystalline inclusion compounds of triclosan with $\beta$-cyclodextrin and its tris-O-methylated derivative. J. Pharm. Biomed. Anal. 2013, 80, 34-43. [CrossRef] [PubMed]

69. Suller, M.T.E.; Russell, A.D. Triclosan and antibiotic resistance in Staphylococcus aureus. J. Antimicrob. Chemother. 2000, 46, 11-18. [CrossRef] [PubMed]

70. Helander, I.M.; Nurmiaho-Lassila, E.-L.; Ahvenainen, R.; Rhoades, J.; Roller, S. Chitosan disrupts the barrier properties of the outer membrane of Gram-negative bacteria. Int. J. Food Microbiol. 2001, 71, 235-244. [CrossRef]

71. Rabea, E.I.; Badawy, M.E.T.; Stevens, C.V.; Smagghe, G.; Steurbaut, W. Chitosan as antimicrobial agent: Applications and mode of action. Biomacromolecules 2003, 4, 1457-1465. [CrossRef]

72. El-tahlawy, K.F.; El-bendary, M.A.; Elhendawy, A.G.; Hudson, S.M. The antimicrobial activity of cotton fabrics treated with different crosslinking agents and chitosan. Carbohydr. Polym. 2005, 60, 421-430. [CrossRef]

73. Cha, D.S.; Chinnan, M.S. Biopolymer-Based Antimicrobial Packaging: A Review. Crit. Rev. Food Sci. Nutr. 2004, 44, 223-237. [CrossRef]

74. Salmieri, S.; Islam, F.; Khan, R.A.; Hossain, F.M.; Ibrahim, H.M.M.; Miao, C.; Hamad, W.Y.; Lacroix, M. Antimicrobial nanocomposite films made of poly(lactic acid)-cellulose nanocrystals (PLA-CNC) in food applications: Part A-effect of nisin release on the inactivation of Listeria monocytogenes in ham. Cellulose 2014, 21, 1837-1850. [CrossRef]

75. Weishaupt, R.; Heuberger, L.; Siqueira, G.; Gutt, B.; Zimmermann, T.; Maniura-Weber, K.; Salentinig, S.; Faccio, G. Enhanced Antimicrobial Activity and Structural Transitions of a Nanofibrillated Cellulose-Nisin Biocomposite Suspension. ACS Appl. Mater. Interfaces 2018, 10, 20170-20181. [CrossRef] [PubMed]

76. Lee, C.H.; Park, H.J.; Lee, D.S. Influence of antimicrobial packaging on kinetics of spoilage microbial growth in milk and orange juice. J. Food Eng. 2004, 65, 527-531. [CrossRef]

77. Tang, J.; Song, Y.; Berry, R.M.; Tam, K.C. Polyrhodanine coated cellulose nanocrystals as optical pH indicators. RSC Adv. 2014, 4, 60249-60252. [CrossRef]

78. Fortunati, E.; Armentano, I.; Zhou, Q.; Iannoni, A.; Saino, E.; Visai, L.; Berglund, L.A.; Kenny, J.M. Multifunctional bionanocomposite films of poly(lactic acid), cellulose nanocrystals and silver nanoparticles. Carbohydr. Polym. 2012, 87, 1596-1605. [CrossRef]

79. Tang, J.; Song, Y.; Tanvir, S.; Anderson, W.A.; Berry, R.M.; Tam, K.C. Polyrhodanine Coated Cellulose Nanocrystals: A Sustainable Antimicrobial Agent. ACS Sustain. Chem. Eng. 2015, 3, 1801-1809. [CrossRef]

80. Unnithan, A.R.; Gnanasekaran, G.; Sathishkumar, Y.; Lee, Y.S.; Kim, C.S. Electrospun antibacterial polyurethane-cellulose acetate-zein composite mats for wound dressing. Carbohydr. Polym. 2014, 102, 884-892. [CrossRef]

81. Zhang, H.; Chen, H.; She, Y.; Zheng, X.; Pu, J. Anti-Yellowing Property of Polyurethane Improved by the Use of Surface-Modified Nanocrystalline Cellulose. BioResources 2013, 9, 673-684. [CrossRef]

82. Wonnie Ma, I.A.; Shafaamri, A.; Kasi, R.; Zaini, F.N.; Balakrishnan, V.; Subramaniam, R.; Arof, A.K. Anticorrosion Properties of Epoxy/Nanocellulose Nanocomposite Coating. BioResources 2017, 12, 2912-2929. [CrossRef]

83. Panda, S.S.; Katz, H.E.; Tovar, J.D. Solid-state electrical applications of protein and peptide based nanomaterials. Chem. Soc. Rev. 2018, 47, 3640-3658. [CrossRef]

84. Csoka, L.; Hoeger, I.C.; Rojas, O.J.; Peszlen, I.; Pawlak, J.J.; Peralta, P.N. Piezoelectric Effect of Cellulose Nanocrystals Thin Films. ACS Macro Lett. 2012, 1, 867-870. [CrossRef]

85. Csoka, L.; Hoeger, I.C.; Peralta, P.; Peszlen, I.; Rojas, O.J. Dielectrophoresis of cellulose nanocrystals and alignment in ultrathin films by electric field-assisted shear assembly. J. Colloid Interface Sci. 2011, 363, $206-212$. [CrossRef] [PubMed]

86. Le Bras, D.; Strømme, M.; Mihranyan, A. Characterization of Dielectric Properties of Nanocellulose from Wood and Algae for Electrical Insulator Applications. J. Phys. Chem. B 2015, 119, 5911-5917. [CrossRef] [PubMed]

87. Kocherbitov, V.; Ulvenlund, S.; Kober, M.; Jarring, K.; Arnebrant, T. Hydration of Microcrystalline Cellulose and Milled Cellulose Studied by Sorption Calorimetry. J. Phys. Chem. B 2008, 112, 3728-3734. [CrossRef] [PubMed] 
88. Mihranyan, A.; Llagostera, A.P.; Karmhag, R.; Strømme, M.; Ek, R. Moisture sorption by cellulose powders of varying crystallinity. Int. J. Pharm. 2004, 269, 433-442. [CrossRef] [PubMed]

89. Gaspar, D.; Fernandes, S.N.; de Oliveira, A.G.; Fernandes, J.G.; Grey, P.; Pontes, R.V.; Pereira, L.; Martins, R.; Godinho, M.H.; Fortunato, E. Nanocrystalline cellulose applied simultaneously as the gate dielectric and the substrate in flexible field effect transistors. Nanotechnology 2014, 25, 094008. [CrossRef] [PubMed]

90. Pereira, L.; Gaspar, D.; Guerin, D.; Delattre, A.; Fortunato, E.; Martins, R. The influence of fibril composition and dimension on the performance of paper gated oxide transistors. Nanotechnology 2014, 25, 094007. [CrossRef]

91. Spinella, S.; Lo Re, G.; Liu, B.; Dorgan, J.; Habibi, Y.; Leclère, P.; Raquez, J.-M.; Dubois, P.; Gross, R.A. Polylactide/cellulose nanocrystal nanocomposites: Efficient routes for nanofiber modification and effects of nanofiber chemistry on PLA reinforcement. Polymer 2015, 65, 9-17. [CrossRef]

92. Xu, S.; Girouard, N.; Schueneman, G.; Shofner, M.L.; Meredith, J.C. Mechanical and thermal properties of waterborne epoxy composites containing cellulose nanocrystals. Polymer 2013, 54, 6589-6598. [CrossRef]

93. Bras, J.; Hassan, M.L.; Bruzesse, C.; Hassan, E.A.; El-Wakil, N.A.; Dufresne, A. Mechanical, barrier, and biodegradability properties of bagasse cellulose whiskers reinforced natural rubber nanocomposites. Ind. Crops Prod. 2010, 32, 627-633. [CrossRef]

94. Cao, Y.; Zavaterri, P.; Youngblood, J.; Moon, R.; Weiss, J. The influence of cellulose nanocrystal additions on the performance of cement paste. Cem. Concr. Compos. 2015, 56, 73-83. [CrossRef]

95. Kedzior, S.A.; Graham, L.; Moorlag, C.; Dooley, B.M.; Cranston, E.D. Poly(methyl methacrylate)-grafted cellulose nanocrystals: One-step synthesis, nanocomposite preparation, and characterization. Can. J. Chem. Eng. 2016, 94, 811-822. [CrossRef]

96. Araki, J.; Wada, M.; Kuga, S. Steric stabilization of a cellulose microcrystal suspension by poly(ethylene glycol) grafting. Langmuir 2001, 17, 21-27. [CrossRef]

97. Habibi, Y.; Goffin, A.-L.; Schiltz, N.; Duquesne, E.; Dubois, P.; Dufresne, A. Bionanocomposites based on poly( $\varepsilon$-caprolactone)-grafted cellulose nanocrystals by ring-opening polymerization. J. Mater. Chem. 2008, 18, 5002. [CrossRef]

98. Azzam, F.; Heux, L.; Putaux, J.L.; Jean, B. Preparation by grafting onto, characterization, and properties of thermally responsive polymer-decorated cellulose nanocrystals. Biomacromolecules 2010, 11, 3652-3659. [CrossRef] [PubMed]

99. Peltzer, M.; Pei, A.; Zhou, Q.; Berglund, L.; Jiménez, A. Surface modification of cellulose nanocrystals by grafting with poly(lactic acid). Polym. Int. 2014, 63, 1056-1062. [CrossRef]

100. Roeder, R.D.; Garcia-Valdez, O.; Whitney, R.A.; Champagne, P.; Cunningham, M.F. Graft modification of cellulose nanocrystals via nitroxide-mediated polymerisation. Polym. Chem. 2016, 7, 6383-6390. [CrossRef]

101. Harrisson, S.; Drisko, G.L.; Malmstr€, E.; Hult, A.; Wooley, K.L. Hybrid Rigid/Soft and Biologic/Synthetic Materials: Polymers Grafted onto Cellulose Microcrystals. Biomacromolecules 2011, 12, 1214-1223. [CrossRef]

102. Morandi, G.; Heath, L.; Thielemans, W. Cellulose Nanocrystals Grafted with Polystyrene Chains through Surface-Initiated Atom Transfer Radical Polymerization (SI-ATRP). Langmuir 2009, 25, 8280-8286. [CrossRef]

103. Jorfi, M.; Foster, E.J. Recent advances in nanocellulose for biomedical applications. J. Appl. Polym. Sci. 2015, 132. [CrossRef]

104. Dong, S.; Roman, M. Fluorescently Labeled Cellulose Nanocrystals for Bioimaging Applications. J. Am. Chem. Soc. 2007, 129, 13810-13811. [CrossRef] [PubMed]

105. Despres, H.; Sunasee, R.; Carson, M.; Pacherille, A.; Nunez, K.; Ckless, K. Cell-based analysis of the immune and antioxidant response of the nanocarrier $\beta$-cyclodextrin conjugated with cellulose nanocrystals. Free Radic. Biol. Med. 2018, 128, S102. [CrossRef]

106. Armentano, I.; Dottori, M.; Fortunati, E.; Mattioli, S.; Kenny, J.M. Biodegradable polymer matrix nanocomposites for tissue engineering: A review. Polym. Degrad. Stab. 2010, 95, 2126-2146. [CrossRef]

107. Domingues, R.M.A.; Gomes, M.E.; Reis, R.L. The Potential of Cellulose Nanocrystals in Tissue Engineering Strategies. Biomacromolecules 2014, 15, 2327-2346. [CrossRef] [PubMed]

108. Yang, X.; Cranston, E.D. Chemically cross-linked cellulose nanocrystal aerogels with shape recovery and superabsorbent properties. Chem. Mater. 2014, 26, 6016-6025. [CrossRef]

109. Lin, N.; Bruzzese, C.; Dufresne, A. TEMPO-oxidized nanocellulose participating as crosslinking aid for alginate-based sponges. ACS Appl. Mater. Interfaces 2012, 4, 4948-4959. [CrossRef] [PubMed] 
110. Zhou, Y.; Fuentes-Hernandez, C.; Khan, T.M.; Liu, J.-C.; Hsu, J.; Shim, J.W.; Dindar, A.; Youngblood, J.P.; Moon, R.J.; Kippelen, B. Recyclable organic solar cells on cellulose nanocrystal substrates. Sci. Rep. 2013, 3, 1536. [CrossRef] [PubMed]

111. Kim, J.-H.; Shim, B.S.; Kim, H.S.; Lee, Y.-J.; Min, S.-K.; Jang, D.; Abas, Z.; Kim, J. Review of Nanocellulose for Sustainable Future Materials. Int. J. Precis. Eng. Manuf. Technol. 2015, 2, 197-213. [CrossRef]

112. Qiu, X.; Hu, S. "Smart" materials based on cellulose: A review of the preparations, properties, and applications. Materials (Basel) 2013, 6, 738-781. [CrossRef]

113. Way, A.E.; Hsu, L.; Shanmuganathan, K.; Weder, C.; Rowan, S.J. PH-responsive cellulose nanocrystal gels and nanocomposites. ACS Macro Lett. 2012, 1, 1001-1006. [CrossRef]

114. Kafy, A.; Akther, A.; Shishir, M.I.R.; Kim, H.C.; Yun, Y.; Kim, J. Cellulose nanocrystal/graphene oxide composite film as humidity sensor. Sens. Actuators A Phys. 2016, 247, 221-226. [CrossRef]

115. Zhang, L.; Li, Q.; Zhou, J.; Zhang, L. Synthesis and Photophysical Behavior of Pyrene-Bearing Cellulose Nanocrystals for $\mathrm{Fe}^{3+}$ Sensing. Macromol. Chem. Phys. 2012, 213, 1612-1617. [CrossRef]

116. Sadasivuni, K.K.; Kafy, A.; Zhai, L.; Ko, H.-U.; Mun, S.; Kim, J. Transparent and Flexible Cellulose Nanocrystal/Reduced Graphene Oxide Film for Proximity Sensing. Small 2015, 11, 994-1002. [CrossRef] [PubMed]

117. Wang, S.; Zhang, X.; Wu, X.; Lu, C. Tailoring percolating conductive networks of natural rubber composites for flexible strain sensors via a cellulose nanocrystal templated assembly. Soft Matter 2016, 12, 845-852. [CrossRef] [PubMed]

118. Annamalai, P.K.; Dagnon, K.L.; Monemian, S.; Foster, E.J.; Rowan, S.J.; Weder, C. Water-responsive mechanically adaptive nanocomposites based on styrene-butadiene rubber and cellulose nanocrystalsProcessing matters. ACS Appl. Mater. Interfaces 2014, 6, 967-976. [CrossRef] [PubMed]

119. Mendez, J.; Annamalai, P.K.; Eichhorn, S.J.; Rusli, R.; Rowan, S.J.; Foster, E.J.; Weder, C. Bioinspired mechanically adaptive polymer nanocomposites with water-activated shape-memory effect. Macromolecules 2011, 44, 6827-6835. [CrossRef]

120. Zoppe, J.O.; Habibi, Y.; Rojas, O.J.; Venditti, R.A.; Johansson, L.-S.; Efimenko, K.; Österberg, M.; Laine, J. Poly( $N$-isopropylacrylamide) Brushes Grafted from Cellulose Nanocrystals via Surface-Initiated Single-Electron Transfer Living Radical Polymerization. Biomacromolecules 2010, 11, 2683-2691. [CrossRef] [PubMed]

121. Zoppe, J.O.; Österberg, M.; Venditti, R.A.; Laine, J.; Rojas, O.J. Surface Interaction Forces of Cellulose Nanocrystals Grafted with Thermoresponsive Polymer Brushes. Biomacromolecules 2011, 12, 2788-2796. [CrossRef]

122. Zoppe, J.O.; Venditti, R.A.; Rojas, O.J. Pickering emulsions stabilized by cellulose nanocrystals grafted with thermo-responsive polymer brushes. J. Colloid Interface Sci. 2012, 369, 202-209. [CrossRef]

123. Bawa, P.; Pillay, V.; Choonara, Y.E.; du Toit, L.C. Stimuli-responsive polymers and their applications in drug delivery. Biomed. Mater. 2009, 4, 022001. [CrossRef]

124. Lin, N.; Dufresne, A. Nanocellulose in biomedicine: Current status and future prospect. Eur. Polym. J. 2014, 59, 302-325. [CrossRef]

(C) 2018 by the authors. Licensee MDPI, Basel, Switzerland. This article is an open access article distributed under the terms and conditions of the Creative Commons Attribution (CC BY) license (http://creativecommons.org/licenses/by/4.0/). 